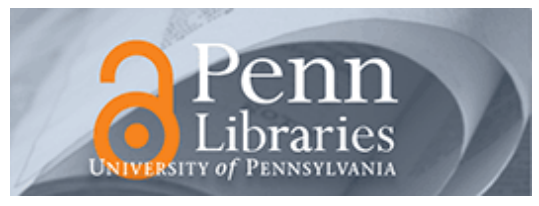

University of Pennsylvania

ScholarlyCommons

Management Papers

Wharton Faculty Research

$12-1-2014$

\title{
A (Blurry) Vision of the Future: How Leader Rhetoric About Ultimate Goals Influences Performance
}

Andrew M. Carton

University of Pennsylvania

Follow this and additional works at: https://repository.upenn.edu/mgmt_papers

Part of the Management Sciences and Quantitative Methods Commons

\section{Recommended Citation}

Carton, A. M. (2014). A (Blurry) Vision of the Future: How Leader Rhetoric About Ultimate Goals Influences Performance. Academy of Management Journal, 57 (6), 1544-1570. http://dx.doi.org/10.5465/ amj.2012.0101

This paper is posted at ScholarlyCommons. https://repository.upenn.edu/mgmt_papers/217

For more information, please contact repository@pobox.upenn.edu. 


\title{
A (Blurry) Vision of the Future: How Leader Rhetoric About Ultimate Goals Influences Performance
}

\author{
Abstract \\ One key responsibility of leaders involves crafting and communicating two types of messages-visions \\ and values -that help followers understand the ultimate purpose of their work. Although scholars have \\ long considered how leaders communicate visions and values to establish a sense of purpose, they have \\ overlooked how these messages can be used to establish a shared sense of purpose, which is achieved \\ when multiple employees possess the same understanding of the purpose of work. In this research, we \\ move beyond the traditional focus on leader rhetoric and individual cognition to examine leader rhetoric \\ and shared cognition. We suggest that a specific combination of messages-a large amount of vision \\ imagery combined with a small number of values-will boost performance more than other combinations \\ because it triggers a shared sense of the organization's ultimate goal, and, in turn, enhances coordination. \\ We found support for our predictions in an archival study of 151 hospitals and an experiment with 62 \\ groups of full-time employees. In light of these findings, we conducted exploratory analyses and \\ discovered two dysfunctional practices: leaders tend to (1) communicate visions without imagery and (2) \\ over-utilize value-laden rhetoric.

\section{Disciplines} \\ Management Sciences and Quantitative Methods
}




\title{
A (Blurry) Vision of the Future: How Leader Rhetoric about Ultimate Goals Influences Performance
}

Andrew M. Carton

The Wharton School, University of Pennsylvania carton@wharton.upenn.edu

\section{Chad Murphy}

College of Business, Oregon State University chad.murphy@oregonstate.edu

\section{Jonathan R. Clark}

Health Policy and Administration, Pennsylvania State University jonrclark@psu.edu

\begin{abstract}
Acknowledgements
For helpful comments at different stages throughout the review process, we thank three anonymous reviewers, Gerry George, Adam Grant, Hajo Adam, Gabe Adams, Sigal Barsade, Dan Cable, Lance Ferris, Ena Inesi, Ben Galvin, Don Hambrick, Samir Nurmohamed, Sara Singer, Niro Sivanathan, colleagues at a seminar at Penn State University, and colleagues at two seminars at Wharton.
\end{abstract}




\title{
A (BLURRY) VISION OF THE FUTURE: HOW LEADER RHETORIC ABOUT ULTIMATE GOALS INFLUENCES PERFORMANCE
}

\begin{abstract}
One key responsibility of leaders involves crafting and communicating two types of messagesvisions and values - that help followers understand the ultimate purpose of their work. Although scholars have long considered how leaders communicate visions and values to establish a sense of purpose, they have overlooked how these messages can be used to establish a shared sense of purpose, which is achieved when multiple employees possess the same understanding of the purpose of work. In this research, we move beyond the traditional focus on leader rhetoric and individual cognition to examine leader rhetoric and shared cognition. We suggest that a specific combination of messages - a large amount of vision imagery combined with a small number of values - will boost performance more than other combinations because it triggers a shared sense of the organization's ultimate goal, and, in turn, enhances coordination. We found support for our predictions in an archival study of 151 hospitals and an experiment with 62 groups of fulltime employees. In light of these findings, we conducted exploratory analyses and discovered two dysfunctional practices: leaders tend to (1) communicate visions without imagery and (2) over-utilize value-laden rhetoric.
\end{abstract}


In August of 1963, Martin Luther King, Jr. united millions of people with a common purpose. During what is widely considered the most influential speech of the past century in the United States (Lucas \& Medhurst, 1999), King presented a vision of the future laced with crisp images, such as "I have a dream that one day, on the red hills of Georgia, the sons of former slaves and the sons of former slave owners will be able to sit down together..."

(usconstitution.net, 2011). Such vivid imagery brought to life a message centered on the values of freedom and equality, infusing new energy into a collective movement that changed the course of history.

Drawing on well-known exemplars, such as Martin Luther King, Jr., researchers have popularized the notion that leaders can inspire action by articulating the organization's ultimate purpose (Bass \& Avolio, 1994; Stam, van Knippenberg, \& Wisse, 2010). Indeed, some scholars have suggested that communicating purpose is the most central of all leader behaviors, because it infuses work with meaning and direction (Nemanich \& Keller, 2007; Shamir, House, \& Arthur, 1993; van Knippenberg \& Sitkin, 2013). One of the primary ways leaders impart purpose is via rhetoric - messages in verbal or written form (Gioia \& Chittipeddi, 1991). In particular, researchers have focused on two complementary messages that leaders use to illuminate purpose: visions and values (Venus, Stam, \& van Knippenberg, 2013). A vision is defined as a vibrant, idealized "verbal portrait" of what the organization aspires to one day achieve (Rafferty \& Griffin, 2004; Waldman \& Yammarino, 1999; Whittington, Goodwin, \& Murray, 2004). Values, such as "superior customer satisfaction" and "success," represent desired end-states as well as guiding principles that provide a sense of purpose by capturing which dayto-day behaviors are important and desirable (Fleishman \& Peters, 1962; Lord \& Brown, 2001; Rokeach, 1973; Russell, 2001; Schwartz, 1992).

Yet while the role of visions and values in establishing a sense of purpose has been widely invoked, the role of these messages in triggering a shared purpose - such as what Martin Luther King successfully achieved in the opening example — has been overlooked. This oversight is surprising. In line with the idea that an organization is a collective geared toward a 
shared purpose (Blau \& Scott, 1962; Parsons, 1956), organizational leadership is considered the act of influencing a collective toward the achievement of a shared purpose (Hemphill \& Coons, 1957; Locke, 1999). Indeed, phrases synonymous with shared purpose, such as "common purpose" and "shared sense of purpose," are widely incanted in the leadership literature (Conger \& Kanungo, 1987; Pearce \& Ensley, 2004; Spencer, 1994; Tsai \& Ghoshal, 1998). It is thus imperative that leaders influence employees not only to acquire a sense of purpose - but a sense of purpose that is construed by different organizational members in the same way.

To understand how leader rhetoric influences the extent to which purpose comes to be shared, we argue that scholars need to augment the current study of how rhetoric influences individual cognition by investigating the way that rhetoric influences shared cognition, which is the study of how different individuals achieve the same understanding of concrete reality and abstract concepts (Ensley \& Pearce, 2001; Thompson \& Fine, 1999; Weick \& Roberts, 1993). By adopting such a lens, we argue that leaders cannot establish a shared sense of purpose merely by coupling a vision and values together when they communicate written and verbal messages to followers. Rather, these rhetorical devices are likely to trigger a common purpose and, in turn, boost performance, only when they are paired in a specific way. Our core premise is that increases in performance gained from a shared purpose are most likely to occur when leaders simultaneously communicate a large amount of vision imagery (e.g., words that describe people, colors, and actions) and a small number of values. The vivid detail gleaned from image-based rhetoric about the future (e.g., "to one day see a city full of hybrid cars") leads employees to share a similar mental image, and the limited amount of conceptual detail gained from a focused value system (e.g., "our core value is environmental sustainability") provides meaning that is construed in a consistent way by different employees. We test this prediction in two studies that use different methodological approaches (archival and experimental). By specifying how rhetoric taps into a subtype of cognition (shared cognition), our findings qualify conventional wisdom by suggesting that coupling a vision with values is necessary, but not sufficient, for establishing a sense of purpose that will positively influence performance. 
In addition to establishing how leaders should use rhetoric, we account for how leaders actually use rhetoric. Through exploratory analyses, we discover that, although leaders regularly invoke visions and values in their rhetoric, they tend to do so in an ineffective way. First, leaders typically transmit visions with concepts (e.g., "to become the world's leading seller of luxury goods") rather than images (e.g., "to see customers smiling as they leave our stores"). This causes organizational members to "consider" the distant future rather than "see" the distant future. Martin Luther King's “I Have a Dream” speech is thus the exception rather than the rule, as most of the visions conveyed by organizational leaders are, ironically, not very visionary. Second, we find that leaders tend to impart a number of values so large as to harm employee sensemaking. In short, leaders tend to craft "blurry" visions rather than vivid ones. They underutilize imagery and then further obscure the clarity of their rhetoric by over-utilizing values.

This article can help scholars revisit assumptions related to one of the foremost responsibilities of leaders: articulating purpose. In highlighting how the influence of vision imagery on key outcomes is contingent on the number of values that leaders express, we investigate characteristics of visions and values that are central to tapping into shared cognition, yet have not been studied in an organizational context. For instance, even though words that trigger a mental image are what make a vision "visionary," such words have not yet been linked to organizational outcomes or studied in tandem with values (cf. Emrich et al., 2001). By focusing on fine-grained elements of leader rhetoric, we answer calls to isolate specific leader behaviors in order to better understand how leaders make an impact (Antonakis, Avolio, \& Sivasubramaniam, 2003; van Knippenberg \& Sitkin, 2013). We also contribute to the leadership literature by highlighting a key discrepancy between what ought to be done and what is actually done with respect to how leaders communicate visions and values. Finally, our findings extend work on shared cognition. Whereas prior research has illuminated how individuals employ sensemaking to construct a common interpretation of past events (Weick, 1995) and present task responsibilities (Cannon-Bowers, Salas, \& Converse, 1990), scholars have rarely considered how leader rhetoric influences a shared understanding of the distant future. 


\section{THE RELATIONSHIP BETWEEN LEADER RHETORIC AND PERFORMANCE}

Several leadership theories assume that employees are motivated by goal hierarchies in which they pursue goals ranging from low-order, short-term goals to high-order, long-term goals (Cropanzano, James, \& Citera, 1993; Kirkpatrick \& Locke, 1996; Nemanich \& Keller, 2007; Whittington et al., 2004). Since high-order goals represent the downstream consequences of achieving low-order goals, they serve as the purpose of low-order action (Harackiewicz \& Elliot, 1998). When invoking high-order goals (and similar concepts, such as "ultimate purposes" and "higher purposes") (Nemanich \& Keller, 2007), leadership scholars typically focus on the very top of the organizational goal hierarchy—what Bateman, O’Neill, and Kenworthy-U'Ren (2002) referred to as "ultimate goals." Ultimate goals represent what leaders consider to be the final level of goal achievement for an organization at a given time.

Individuals can process any phenomenon concretely (such as an image of a customer smiling while using a product) or conceptually (such as the meaning of "customer satisfaction") (Kroll \& Merves, 1986). This dichotomy reflects the fact that the mind is structured into two systems (Epstein, 1998). The first system encodes concrete information about external realitythat which appeals to the senses. The second system processes logic and meaning-how pieces of information are classified and associated with one another (Kroll \& Merves, 1986). In the case of ultimate goals, scholars who have articulated the role of a vision typically use terms (e.g., "clear" and "vivid") as well as phrases (e.g., "portrait of the future," "what the future will look like") that suggest that the vision is the linguistic device that can be used to communicate an ultimate goal concretely (Rafferty \& Griffin, 2004). Alternatively, because values capture the meaning of the future in terms of general end-states and guiding principles (Rokeach, 1973), they are considered to be the primary linguistic device for describing ultimate goals conceptually. ${ }^{1}$

\footnotetext{
${ }^{1}$ Nothing precludes a vision or value from representing both a desired future state and a present state (Rokeach, 1972). For instance, a vision to "make people laugh" (the former vision of a movie studio) and the value to "act courteously toward customers" (the core value of a bank) can be achieved both in the present and in the distant future. This is consistent with the idea that an individual or organization can reach the final level of a goal hierarchy (i.e., its ultimate goal) and look to sustain this level of accomplishment (Bateman et al., 2002). Alternatively, a
} 
Since individuals gain deeper understanding when they possess both concrete and conceptual representations of a given phenomenon (Weick, Sutcliffe, \& Obstfeld, 2005), the assumption that a vision and values can combine to create a comprehensive sense of an organization's ultimate goal appears sensible (Collins \& Porras, 1994; Fu, Tsui, Liu, \& Li, 2010; Kotter, 1996; Yukl, 1998). Yet how do leaders move beyond helping employees gain an understanding of the ultimate goal to helping multiple employees gain the same understanding of the ultimate goal - the "shared" component of a shared sense of purpose? As shown in Figure 1, we predict that (1) the number of image-based words (i.e., amount of vision imagery) articulated by leaders triggers a shared ultimate goal, (2) a shared ultimate goal increases coordination, and (3) coordination increases performance quality. The number of values articulated by leaders moderates the first two of these three causal pathways.

Insert Figure 1 About Here

\section{The Consequence of Leader Rhetoric: A Shared Ultimate Goal}

How image-based words trigger a shared ultimate goal. As noted above, researchers have distinguished the role of a vision from other forms of rhetoric by suggesting that a vision should be vivid and clear, akin to a "verbal portrait" (Collins \& Porras, 1994; Emrich, Brower, Feldman, \& Garland, 2001; Hartnell \& Walumbwa, 2010; Rafferty \& Griffin, 2004; Rowden, 2000; Waldman \& Yammarino, 1999; Whittington et al., 2004). True to the literal meaning of "vision," these perspectives suggest that the distinguishing feature of a leader's vision is its ability to yield a concrete image than can be seen in the "mind's eye." Surprisingly, however, little research has directly examined the property of language that gives a vision this potential: image-based words (cf. Emrich et al., 2001). According to Emrich et al. (2001), a greater number of image-based words used by a leader in a vision will trigger a stronger mental

leader may view the status quo as insufficient, and thus both its vision and values may strictly represent future aspirations. For the purposes of our analysis, a critical underlying assumption is that visions and values represent two different ways that leaders clarify what can ultimately be achieved in the distant future, regardless of whether that future requires maintaining or improving on the status quo. 
image — a simulated real life scenario. Words that are not processed as mental images are processed at a conceptual level (Nisbett \& Ross, 1980). A review of research in psycholinguistics and cognitive psychology suggests that image-based words include: nouns with recognizable physical attributes versus nouns with uncertain physical attributes (e.g., “children” versus “customers”) (Hoffmann, Denis, \& Ziessler, 1983); verbs that indicate observable actions versus verbs that do not (e.g., "smile" rather than "enjoy") (Hale, 2012); and objects, people, and actions that are very familiar (e.g., "parents") (Besson, Ceccaldi, Didic, \& Barbeau, 2012). We hereafter refer to image-based words only as they are used in a leader's vision of the future and vision imagery as the concrete representations of the future that are triggered by image-based words in a vision.

Emrich et al. (2001) proposed that image-based words influence individual level psychological states (e.g., emotions) as well as the attributions individuals make about leaders. Since this study was based on individual-level attributions, it did not look at organizational or collective outcomes. We suggest that image-based words represent the core dimension of a vision responsible for triggering a shared ultimate goal. Image-based words depict a scenario as one would directly observe it in the world. Leaders who use words that reflect how the world is directly observed will cause followers to have strongly overlapping cognitive representations, because there is substantial commonality across people in terms of how external reality is construed (Guadagno, Rhoads, \& Sagarin, 2011; Nisbett \& Ross, 1980). For example, there will be more consistency across individuals in terms of how the word "laugh" is construed than how the term "enjoy" is construed. "Laugh" equates to an observable behavior, whereas "enjoy" ties not to a specific behavior, but to an array of possible behaviors and feelings, some of which may not be directly observable. For this reason, as a leader's vision triggers stronger mental imagery, employees within and across units are more likely to "see" the distant future in a similar way, increasing the likelihood that members will achieve a shared representation of the ultimate goal. See Path A in Figure 1. However, we suggest that a vision with image-based words is 
necessary — but not sufficient—for establishing a shared ultimate goal. Rather, leaders must also articulate a small number of values.

The moderating role of how leaders articulate values. One key characteristic of cognition is that a single mental image can be interpreted differently by being connected to different concepts (de Groot, 1989; Song, Tian, \& Liu, 2012). People are likely to adopt the interpretation of a mental image that is most salient to them (de Groot, 1989). Leaders can make certain interpretations more salient than others through the values they explicitly invoke. When leaders pair image-based words with a small number of explicitly stated values, recipients of the leader's message will converge more strongly toward the same interpretation of the image described in the leader's vision. It is useful to consider the extreme case: when a leader articulates an image-based vision while also articulating a single value. For instance, a toy manufacturer's vision of their toys making children laugh can be tied to the value of "superior customer service.” In this case, multiple employees are likely to link the same mental image to the same value.

In contrast, as a leader explicates a greater number of values in tandem with a vision with image-based words, different organizational members are more likely to ascribe different meanings to the mental image derived from the vision (Weick, 1995). If a leader presents the vision in the previous paragraph and then notes that "we will exhibit superior customer service, demonstrate outstanding performance, act accountably toward our customers, and develop quality products," then one member may believe the vision means "superior customer service," another may believe it means "outstanding performance" and another may believe it means “developing quality products.” In this way, leaders who articulate a greater number of values fracture collective sensemaking. Even if members "see" the same mental image, they interpret its meaning differently. This is sufficient to impair the establishment of a shared ultimate goal. Since we posit that employees rely on both image-based and values-based rhetoric simultaneously in order to understand the organization's ultimate goal, a theoretically equivalent way of articulating our argument is that a leader's expression of a focused value system is 
insufficient on its own for triggering a shared ultimate goal; values will remain nebulous if they are not "brought to life" by vision imagery, allowing multiple actors to acquire the same understanding of how values can be translated into real life outcomes.

Given that image-based words are easier to recall than conceptual words (Walker \& Hulme, 1999) and a small number of conceptual words are easier to recall than a large number (Miller, 1956), this pairing of messages not only leads members to initially converge toward the same representation of the ultimate goal, but to benefit from that representation being further reinforced by collective memory. In short, our arguments suggest a symbiotic, interactive effect between vision imagery and values-based rhetoric: leaders must invoke both image-based words and a small number of values since these two forms of rhetoric need to be connected to each other in order to create a shared understanding of the ultimate goal (Weick et al., 2005). See Path A in Figure 1.

\section{The Consequence of a Shared Ultimate Goal: Enhanced Coordination}

How a shared ultimate goal drives coordination. When an ultimate goal is shared among a collective, individuals are more likely to channel effort toward the same understanding of downstream consequences (e.g., what state the organization aspires to reach as a function of meeting low-order objectives). As such, a shared representation of an ultimate goal focuses attention across actors (Ocasio, 1998) and provides a common interpretative frame (Fussell \& Krauss, 1989). The utility of a shared ultimate goal becomes more evident when considering the often chaotic realities of organizational life. As noted by Hackman (1987), tasks are often too complex to have all parameters clearly outlined for each member. This can lead members to arrive at different interpretations of what they should be doing, muddying the coordination process. Such confusion can be avoided if there is a reference point that all members share in common. When an ultimate goal is collectively shared, different individuals use the same representation of the distal purpose of work to focus attention (Ocasio, 1998) and fill in "gaps" in task instructions in similar ways, reducing confusion with respect to giving instructions and synchronizing actions. 
Another benefit of a shared ultimate goal relates to how it leads organizational members to take a "big picture" view of a task. Research on temporal construal has shown that as individuals think further out into the future, they tend to adopt a broader view of the system in which they are working (Liberman \& Förster, 2009; Wakslak, Trope, Liberman, \& Alony, 2006). Thus, ultimate goals trigger individuals to adopt not only a long term view of the organization, but also a broad view of the organization. In this way, organizational members who share the same understanding of the long term are likely to collectively adopt a "global focus" rather than a purely "local focus" (Senge \& Sterman, 1992), whereby each individual realizes that he or she is not just working on a task in isolation, but instead must align his or her responsibilities with those of others. Each actor is more likely to understand that certain goals cannot be achieved without every person doing his or her part. For this reason, members act heedfully to keep the broader system of roles and interactions between employees intact and functioning properly.

In this manner, a shared ultimate goal facilitates the achievement of "collective mind" (Weick \& Roberts, 1993), whereby any given individual can more easily sense the collection of interdependent roles that constitute a system and understand how he or she can personally contribute to it. Weick and Roberts (1993) argued that the achievement of collective mind is critical for preventing coordination problems because it signals that constituent actors possess awareness beyond their immediate responsibilities. By sensing that her role is just one part of a larger system, a member takes the perspective of others and assumes extra care in orchestrating her actions with those of others. Whereas an unclear representation of the ultimate goal will confuse or fracture attention and effort, a shared ultimate goal will lead individuals to align efforts more readily. When multiple individuals use the same understanding of the organization's ultimate goal to act more heedfully toward others who depend on them, processes that are a function of interdependent action are boosted (Cyert \& March, 1963; Gittell, 2002). This collective effort to take a broader view of the system is likely to be especially valuable for transactions that occur between individuals with different specializations, as these types of 
interactions are particularly vulnerable to coordination problems (Dougherty, 1992; Tushman \& Scanlan, 1981). The relationship between a shared ultimate goal and coordination is depicted by Path B in Figure 1.

The moderating role of how leaders articulate values. In addition to impacting the causal path between image-based words and a shared ultimate goal, the number of values stated by a leader can also influence the causal path between a shared ultimate goal and coordination. A small number of values is likely to contribute to a strong culture, in which individuals share the same general understanding of which types of actions are encouraged and which are discouraged during task implementation (O'Reilly, Chatman, \& Caldwell, 1991; Wiener, 1988). Since values are high-order constructs, they do not directly specify which behaviors are appropriate. Rather, they serve as general standards for guiding conduct during task work (Gruys, Stewart, Goodstein, Bing, \& Wicks, 2008). When multiple individuals have the same understanding of how to act during the implementation phase of a task, the link between a shared ultimate goal and coordination will be boosted.

Alternatively, a larger number of values splays clarity attained from image-based words and a shared ultimate goal, impairing the ability of employees to coordinate their actions around a common sense of how to behave (Denison \& Spreitzer, 1991). This may happen in two ways. First, different employees may be guided by different values. For instance, a hospital leader who communicates multiple values (e.g., efficiency, accountability, quality, integrity, and innovation) may lead hospital employees to be guided by different implicit protocols while working. A physician may look to the value of efficiency (worrying less about quality and more about quantity) while a nurse may be more focused on quality of care. The physician may dictate instructions with speed in mind rather than with detail in mind. This may cause the physician to craft hastily written instructions, leading to a greater incidence of errors. In contrast, the nurse may seek to generate a carefully orchestrated plan for each patient. Second, the existence of multiple values may cause individuals to differ in their interpretation of each of the individual values. Continuing the example above, the physician who focuses on "efficiency" might be led 
to believe that "accountability" means accountability to the hospital hierarchy, because such an emphasis is more likely to yield an efficient process. On the other hand, the nurse who stresses "quality" might be led to conclude that "accountability" means being accountable to patients, because such a focus is more likely to yield quality outcomes. Due to their different points of emphasis, coordination between the physician and nurse is ultimately harmed.

\section{The Consequence of Enhanced Coordination: Increased Performance Quality}

Enhanced coordination improves performance quality (e.g., the quality of a product design or the effectiveness of a service) because it leads the skills and responsibilities of different individuals to better fit the task at hand (Van de Ven, Delbecq, \& Koenig Jr, 1976). Coordination proxies synergy, in that a set of component parts work together to harness and magnify their unique capabilities. Particularly likely to benefit from enhanced coordination are tasks that simultaneously require a great degree of role specialization and interdependence, especially conjunctive tasks in which one person could not perform his or her task effectively without another person first performing his or her task sufficiently. For instance, employees responsible for developing a new product will be able to introduce value-added nuances into the product design if they are able to communicate with each other smoothly. When individuals consider the impact that their actions have on others, they are more likely to stay attentive to the hindrances and barriers to mutual understanding that mar task performance (Gittell, 2002). In sum, the increased coordination engendered by a shared representation of purpose should boost performance quality. This causal relationship is depicted by Path $\mathrm{C}$ in Figure 1.

Altogether, our arguments lead us to make two predictions - one related to how the number of values expressed by a leader moderates the direct effect of image-based words on performance, and the other related to how the number of values expressed by a leader moderates the indirect effect of image-based words on performance.

Interaction between vision and values. The solid lines in Figure 1 show how vision and values interact to influence performance directly. We expect that both types of rhetoric work together: values give meaning to a vision and a vision brings values to life. However, for this 
symbiosis to occur, different organizational members must process both types of messages in the same way. Leaders who convey a vision with image-based words cause organizational members to not only visualize a future scene, but the same future scene. Leaders who express a small number of values cause organizational members to not only ascribe these image-based words with meaning, but the same meaning. A vivid vision is not enough; the clarity of a portrait of the future is only useful to the extent that this portrait has a clear meaning. Likewise, a focused set of values is not alone sufficient. Image-based words are needed to bring these values to life by leading organizational members to reach the same understanding of how abstract concepts can be realized.

Hypothesis 1: When leaders communicate rhetoric about ultimate goals, the number of image-based words and the number of values will interact, such that the positive effect of image-based words on performance quality will weaken as the number of values increases.

Conditional indirect effect. The dashed lines in Figure 1 show how we disentangle the causal mechanisms responsible for this interaction. For the first causal path (Path A), we propose that a greater number of image-based words in a leader's vision increases the extent to which an ultimate goal will be shared. However, this causal pathway will be conditional on the number of values communicated by leaders. Compared with leaders who articulate a small number of values, leaders who articulate a large number of values will undermine the extent to which their expression of image-based words promotes a shared representation of the ultimate goal. For the second causal path (Path B), we propose that a shared ultimate goal boosts coordination. However, this causal pathway will also be conditional on the number of values communicated by leaders: a small set of values provides a focused set of standards related to behaviors that are appropriate as employees implement task responsibilities, thereby boosting coordination. For the third causal path (Path C), we predict that coordination enhances performance quality. In short, we distinguish the two moderating roles of values from each other by adopting and slightly modifying the notion of espoused versus enacted values (Schuh \& Miller, 2006). Although this distinction has resided in the study of the content of values, we 
extend it to understand the effect of the number of values: a small set of espoused values enhances the link between leader expressions of image-based words and follower cognition (Path A), and then this same small set of values enhances the link between follower cognition and behavior when the values become enacted during the implementation of a task (Path B).

Hypothesis 2: When leaders communicate rhetoric about ultimate goals, the positive indirect effect between the number of image-based words, a shared ultimate goal, coordination, and performance quality (i.e., image-based words $\rightarrow$ shared ultimate goal $\rightarrow$ coordination $\rightarrow$ performance quality) will weaken as the number of values increases.

\section{OVERVIEW OF CURRENT RESEARCH}

Since no single study can combine internal and external validity as effectively as two studies that use different methods with offsetting weaknesses (Campbell \& Fiske, 1959), we tested Hypothesis 1 with an archival study of hospitals and Hypotheses 1 and 2 in an experiment with full-time employees and data from four separate sources. We examined performance quality among collectives in both studies. Both study contexts featured similar tasks. In the hospital cardiology units featured in study 1, (1) physicians provided instructions to discharge nurses who were responsible for coordinating the release of patients from the hospital, (2) these instructions were usually sent electronically, and (3) the nurse had to interpret the instructions to make decisions. In the toy company context featured in study 2, (1) designers conjured ideas for new toys and provided instructions on how to build them, (2) these instructions were sent electronically, and (3) those responsible for procuring materials had to interpret the instructions to make decisions. To be sure, there are many factors beyond coordination of these focal actors that determine performance in hospitals, toy companies, and other contexts. However, we attempted to control for these factors in the archival study, and our experimental study held these factors constant.

\section{STUDY 1: ARCHIVAL DATA}

\section{Sample and Independent Variables}

We began with the entire population of short term, acute care hospitals in the U.S. state of California (332 hospitals). To test our theory, we sought proxies of the type of rhetoric 
leaders use to help followers build representations of ultimate goals (a) on a daily basis and (b) during critical sensegiving periods, as both forms of communication are likely to have a proximal impact on employee cognition and behavioral outcomes (Gioia \& Chittipeddi, 1991). As unobtrusive proxies of these forms of leader rhetoric, we sampled vision and values statements on hospital websites. ${ }^{2}$ Of the 332 hospitals in the sampling frame, there were 151 total hospitals with identifiable vision statements, 111 of which also had values statements (see below for our empirical treatment of missing values statements). After we describe how we collected and measured both types of statements, we explain validation tests we undertook to substantiate our assumption that these statements serve as unobtrusive proxies of the rhetoric that leaders use on a regular basis as well as during critical sensegiving periods.

Data collection and coding. Two coders assessed image-based words ${ }^{3}$ based on the properties of language that induce imagery, which were described in the introduction. An example of a sentence from our sample with a large number of image-based words was one that stated "our vision would be realized" when "donors tell friends and neighbors that gifts to [hospital name] are among the best decisions they have ever made." One example of a vision statement from our sample that only contained conceptual language is a vision for a hospital to "distinguish itself for its achievement of excellence in quality outcomes." Each codable word was rated from 0 to 10 , whereby a word associated with a weak image yielded 0 points and a word associated with a strong image yielded 10 points. The points for all of the words were then added together to determine a final image strength score for each statement. Inter-rater reliability among the coders was strong, $\mathrm{ICC}=.877$. Inter-rater agreement was also strong $(\mathrm{AD}=.498$, or a deviation of one half of a word, which is substantial considering that the range of image-based phrases was .5 to 23 per statement). As a robustness check on the coding, a research assistant

\footnotetext{
${ }^{2}$ To ensure that vision statements were intended to be visions of the future, we only included statements that began with "Our vision is...," or that were branded underneath a heading entitled "Vision" or "Vision Statement." For hospitals with vision statements, we counted the number of values in values statements. We used similar discretion with respect to what was considered a value, counting values when they appeared after a phrase such as "Our values are" or were branded underneath a heading entitled "Values Statement."

${ }^{3}$ In some cases, phrases and terms composed of more than one word were coded as a single word when these phrases and terms were meant to convey a single idea.
} 
collected an objective measure of image-based words (the number of verbs per vision statement that denote observable behaviors) for a subsample of the analyses. Although, as noted above, there are several other components of language that feed into mental imagery, this objective metric can serve as a useful barometer. Indeed, we found a moderately strong correspondence between the subjective and objective measures $(r=.6)$.

With respect to our measure of the number of values in values statements, we relied on several sources (Brown \& Trevino, 2006; Chatman, 1989; Hansen, 2010; O'Reilly et al., 1991). In particular, we focused on the idea that a value is a concise, abstract description of a "desired end-state." A value had to be stated as if it were representing the organization rather than an individual. Typically, values statements reflected speech patterns of leaders because a single value would be introduced (e.g., "innovation"), and then there would be a brief description of the value and an explanation of how it applies to the organizational context.

Validation of measures. In order to verify that vision and values statements serve as proxies for leader rhetoric, we gathered quantitative and qualitative data in three waves from 42 organizations spanning several industries. To determine whether formal organizational statements represent the rhetoric of upper echelon leaders, we first conducted interviews with 34 upper echelon leaders (typically CEOs) from 34 of the 42 organizations, selected through a stratified search according to (1) U.S. region, (2) size, and (3) industry. In each organization, we initially contacted top managers in an effort to identify which employees were responsible for crafting the organization's vision statement. If there was a group of people who crafted the statement, we asked probing questions to determine which person may have been its chief designer. We then contacted the person who had first-hand experience with developing the vision statement; we found that it was always someone inside the organization. A total of 34 leaders (each of whom was from a separate company) responded to these emails, a $64 \%$ response rate. The final sample was $26.5 \%$ female. In each case, the person was a top manager at the company, in the sense that he or she belonged to the highest level of management in the organization (Hambrick \& Mason, 1984). In most cases, the leaders said that they 
communicated the vision statement on many occasions and in many contexts, including verbally during company meetings, and in writing on office walls and within internal memos. Most respondents suggested that crafting visions was extremely important in the company for motivating employees and directing them toward a common long-term goal. For instance, one respondent stated her company's vision "was only a 20 word statement, but it was extremely important," and therefore she spent two years re-crafting the vision statement.

The average length of the interviews was 15-20 minutes. We asked them to speak about the distant goals of their organization. After transcribing the text of their interviews, we compared the content of their organization's vision statements with the content of their rhetoric, coding both in terms of imagery and concepts using the method reviewed above. Results of ordinary least squares regression (controlling for several factors, including word length and industry) demonstrated that the usage of image-laden rhetoric in vision statements predicted the usage of image-laden rhetoric in speech, $b=.584, p<.05$. This suggests that official statements are potentially effective as unobtrusive measures of leader rhetoric in ongoing conversation. In all likelihood, the wording in the statements and the rhetoric that leaders use on a daily basis reinforce each other. For instance, visionary leaders may craft image-laden vision statements and these statements, in turn, are likely to affect the language they use when discussing the organization's ultimate goal.

We then undertook a second wave of data collection to test whether the rhetoric of leaders at the top of the organization has "trickle-down" effects, wherein the rhetoric of leaders at lower levels in the organization also reflects the vision and values statements (Hambrick \& Mason, 1984; Raes, Heijltjes, Glunk, \& Roe, 2011). To assess this possibility, we collected qualitative data by watching archived videos of employees from 2 of the 42 organizations. We identified one hospital with a vision statement that had strong imagery and one hospital with a vision statement that had weak imagery, and then used internet search engines to find videos that had been published online, resulting in archived video clips of 25 total employees. The videos were found through internet search engines, and were typically sponsored by the hospitals 
themselves. We found that the only instances of mid-level leaders using image-based words in informal speech occurred in the hospital with the strong imagery vision statement.

Finally, we collected qualitative data at 6 of the 42 organizations. Across all six organizations, leaders referenced the vision and values statements during critical junctures of identity formation, enculturation, and learning (Levitt \& March, 1988). During these critical periods, collective attention was usually directed at the same upper echelon leader, and organizational members were likely to be particularly attuned to their distinctive purpose as an organization. As specific examples of these critical periods, we found that leaders mentioned the vision and values during orientation, training, annual company-wide recognition ceremonies, holiday parties, and meetings in which the organization was determining its strategic direction. It is possible that the effect of leader rhetoric is stronger during and immediately after these critical junctures, however this does not preclude a cumulative effect of leader rhetoric on performance through the causal mechanisms we have proposed. When gathering these qualitative data, we also discovered that leaders communicated the vision and values in various forms of writing. One organization positioned the values on bulletin boards in its hallways while placing the vision on easels in various rooms and on television monitors at the entrance to the building. Another placed its core value on a large overhead banner. These practices reflect the hospitals from our sample, one of which explicitly noted that its vision was posted on office walls.

Altogether, these three waves of quantitative and qualitative data suggest that vision and values statements reflect the ongoing rhetoric of leaders across different organizational levels, especially during the above-mentioned critical junctures (e.g., orientation).

\section{Dependent Variables}

We obtained data on performance quality from the Centers for Medicare and Medicaid Services in the U.S. Department of Health and Human Services at hospitalcompare.hhs.gov. We examined readmission prevention for patients admitted with a heart attack, measured as the percentage of Medicare patients who were not readmitted to the hospital within 30 days 
following discharge. ${ }^{4}$ Heart attack readmission prevention represents an appropriate measure of quality because it indicates the extent to which cardiology units provide effective treatment for the leading cause of death in the United States. As noted earlier, this factor can be influenced by coordination between the patient's physician and the nurses who oversee patient discharge (Benbassat \& Taragin, 2000; Cooper, Sirio, Rotondi, Shepardson, \& Rosenthal, 1999). The more effective the treatment, the less likely the patient will need to return for follow-up care. ${ }^{5}$ From the sample of 151 hospitals, 92 hospitals had full heart attack readmission prevention data. ${ }^{6}$

\section{Control Variables}

Coders were trained to assess several control variables. We controlled for specificity of the vision because more specific information is likely to lead to better performance (Locke \& Latham, 1990). We measured the prosocial impact of the vision with a four-item scale from Grant (2008) since visions often have overtones of prosocial behavior (Grant, 2012). We measured perceived importance of the vision since more important visions may trigger greater investment, as they indicate that the vision has a stronger appeal, or valence (Vroom, 1964). Additionally, we controlled for the perceived difficulty of attaining the vision (Locke \& Latham, 1990). We also controlled for the fluency of the vision statement with the Gunning-Fog index (Gunning, 1968). Research on fluency suggests that individuals prefer phrases that are easier to process cognitively (e.g., fewer syllables, shorter words) (Shah \& Oppenheimer, 2007).

\footnotetext{
${ }^{4}$ To make fair comparisons across hospitals, this measure must be adjusted for patient risk. Medicare does so by taking into account a patient's age, gender, past medical history and any other diseases or conditions the patient had upon his or her arrival at the hospital.

5 As a robustness check, we used the California Office of Statewide Health Planning and Development site to collect data on a second dependent variable: return on assets. ROA is a widely used measure of accounting profit in the strategy literature (McGahan \& Porter, 2002). Though hospitals vary in their orientation towards profit-making, and we attempt to control for this (see below), all hospitals must produce sufficient accounting profit to cover their operations and fund future needs. Firms that experience better coordination by virtue of a shared ultimate goal should accrue stronger returns on assets. We acknowledge, however, that the theoretical link between shared ultimate goals, coordination, and performance may or may not hold for ROA since it is a financial measure rather than a measure of performance quality. From the sample of 151 hospitals, 143 hospitals had full data.

${ }^{6}$ We examined sampled hospitals relative to hospitals that were not sampled (i.e., those without publicly available vision statements or with other missing data) on a series of variables, including CEO tenure, organization size, performance, competition, teaching intensity, technological status and whether the hospital was public or private, to ensure that our sample did not differ from excluded hospitals. These analyses suggested that the two groups did not differ in any systematic way.
} 
Additionally, we controlled for CEO tenure in order to capture the possibility that the length of CEO service is related to both performance and the tendency to use certain types of rhetoric. In addition, we included hospital size (total admissions). Size confers advantages in terms of resources and performance. Further, leaders may craft rhetoric differently when they represent more constituents. Membership in a multi-hospital system was included to capture the possibility that structural differences across organizations may confer advantages in terms of management expertise and market power (Bazzoli, Shortell, Dubbs, Chan, \& Kralovec, 1999). Further, this measure captures the degree of hierarchical control that facility (vs. system) leaders have. We included a Herfindahl index based on market share in each hospital's health referral region in order to control for the influence that the competitive environment may exert on performance. We also included an indicator of ownership status - government versus privatein order to take hold of differences in organizational mission.

To assess the degree to which hospitals are engaged in more complex levels of care and possess better resources, we controlled for the extent of teaching activities and the average technical complexity of services, based on an index developed in the medical literature (Landon et al., 2006). We included the share of patients on Medicaid because Medicaid patients tend to have more serious diseases than otherwise comparable patients. Since more specialized hospitals have a more differentiated focus and may perform at a higher level (Clark \& Huckman, 2012), we controlled for specialization by calculating the ratio of the patient volume in the hospital's largest service line to the hospital's total volume (Greenwald et al., 2006). Finally, in order to capture the extent to which hospitals are able to attract better nurses and doctors, we included each hospital's magnet status (yes/no) and its presence (or absence) on any of the U.S. News and World Report hospital rankings in 16 specialty areas. Magnet status is conferred by the American Nurses Credentialing Center, and U.S. News and World Report rankings are based in part on a facility's reputation among physicians in a given specialty. 


\section{Endogeneity Checks}

To reduce concerns related to endogeneity, we employed three categories of checks that Wooldridge (2001) and other econometricians have recommended. The first concerns reverse causality - the possibility that performance drives the usage of image-based words rather than, as we theorize, the other way around. We conducted tests recommended by Edwards (2008). Results suggested that performance in 2009 did not predict image-based words in 2010 (the year we used in our analyses). This reduced concerns that better performing hospitals set vision statements differently than worse performing hospitals. To further rule out reverse causality as well as the possibility that current performance was related to the previous year's performance, we controlled for the prior year's performance (Chatterjee \& Hambrick, 2007). The second endogeneity concern relates to omitted variable bias. Beyond the large set of controls we discuss above (which led the baseline models with controls to explain a large amount of variance in the dependent variables), we conducted robustness checks with a longitudinally determined variable that proxies CEO capabilities. ${ }^{7}$ All results reported below held when this variable was included. As another way to address the possibility of omitted variable bias, we conducted propensity score matching analyses (Peikes, Moreno, \& Orzol, 2008) with a dichotomized version of our imagery variable. Our results held, further reducing concerns about possible confounds. The third endogeneity concern relates to measurement error. The validation tests (described above) addressed this concern.

\section{Results and Discussion}

See Table 1 for descriptive statistics and correlations. We estimated our models using ordinary least squares (OLS) regression and employed robust (Huber-White) standard errors to

\footnotetext{
${ }^{7}$ We used 10 years of ROA performance data to build a model that accounts for effects at different levels of analysis (organizational, system, market, macro-economic) and that isolates changes in performance over a ten year period that may be attributable to the CEO. We were only able to approximate this factor for return on assets because data on heart attack readmissions only existed for the last few years. Although we remain agnostic as to which leader or leaders craft visionary and values-laden rhetoric, the most influential leader is most likely to be the CEO because the CEO crafts or approves the hospital's vision and values statements. Further, the CEO's rhetoric is the most influential and the most likely to cascade downward (Hambrick \& Mason, 1984; Raes et al., 2011).
} 
address the possible presence of heteroscedasticity. The results of these estimates are reported in Table 2, with standardized beta coefficients included in parentheses.

Insert Tables 1 and 2 About Here

Our prediction that there would be an interaction between image-based words and the number of values (Table 2, Column 3 ) on heart attack readmission prevention was supported ( $b$ $=-.008, p<.05)$. Image-based words had a stronger relationship with performance quality as the number of values decreased. The simple slope for image-based words was significant at 1 value $(b=.037, p<.01)$ and at 3 values $(b=.021, p<.01)$, and non-significant at 5,7 , and 9 values. See Figure 2. In probing these data further, we found that the estimated slope of the strong imagery effect was only positive when leaders expressed 4 or fewer values. This effect equates to meaningful practical differences. A large number of image-based words (one standard deviation above the mean) equals about two fewer heart attack patients requiring readmission per hospital per year (equaling about 600 patients across all California hospitals) when the number of values was approximately one standard deviation below the mean ( 1 value), but the relationship between image-based words and readmission prevention became significantly weaker when the number of values was approximately one standard deviation above the mean. ${ }^{8}$

The imagery variable used in our analysis was positively skewed, so only a handful of hospitals could be classified as having vision statements with a large number of image-based words. In order to ensure that our findings were not disproportionately influenced by a small number of observations, we calculated statistics aimed at determining the influence of specific observations on the reported estimates. ${ }^{9}$ Our results remained significant when influential

\footnotetext{
${ }^{8}$ As a robustness check, the interaction between image-based words and the number of values was also significant for ROA $(b=-.001, p<.01)$. Simple slopes followed the same patterns as the slopes for heart attack readmission prevention.

${ }^{9}$ We conducted (1) dfits, which evaluates an observation's influence on the estimates overall, and (2) dfbeta, which evaluates an observation's influence on the estimated coefficient for a specific variable (e.g., vision imagery) (Bollen \& Jackman, 1985). We calculated these statistics for both the models with heart attack readmission prevention and return on assets. Our analysis of these statistics revealed that, based on generally accepted thresholds for acceptability for these statistics (2/sqrt(n) for dfbeta; $2 * \operatorname{sqrt}(\mathrm{k} / \mathrm{n})$ for dfits), 13 observations were deemed to be
} 
observations were removed. In fact, the effect sizes became larger. Finally, our results remained significant when including a dichotomous variable that captured whether there are differences between organizations with no explicitly stated values and those with explicitly stated values.

Insert Figure 2 About Here

Our results provide strong support for our hypotheses in an external setting. The validated measures and robustness checks on our findings (usage of ROA and parameter stability checks) provide greater assurance. These results are even more notable when considering the large R-square for the baseline model with controls, which explained nearly $40 \%$ of the variance in ROA and over $59 \%$ of the variance in heart attack readmission prevention. The practical impact of the findings is notable given that altering one's rhetoric does not constitute a costly change. But how leaders should craft rhetoric says nothing about how leaders actually craft rhetoric. Exploratory analyses on the same sample of hospitals from this study demonstrate that the majority of hospitals craft vision statements with far more conceptual words than image-based words. ${ }^{10}$ Further exploratory analyses suggest that the suboptimal usage of rhetoric extends to how leaders communicate values, as the average number of values communicated by leaders (more than four) is likely to obscure the influence of vision imagery, since the effect of imagery on performance only holds when there are four values or less. ${ }^{11}$ In sum, most leaders exhibit a "blurry vision bias" in which they (1) provide conceptual (rather than concrete) visions and then (2) communicate a number of values that further obscures the

influential in the analysis of return on assets, and 7 were deemed to be influential in the heart attack readmissions analysis. Results sustained when these outliers were removed.

${ }^{10}$ We found about sixteen conceptual words per vision statement versus one image-based word per vision statement. For instance, in a subsample we calculated that fewer than $8 \%$ of hospitals depicted observable behaviors in their vision statements. We conducted a similar analysis on a randomly selected sample of 30 Fortune 500 companies and found that only 3 of these companies depicted observable behaviors in their vision statements. ${ }^{11}$ The average number of values that leaders in our hospital study communicated was 4.9, and leaders who articulated above-average numbers of image-based words in their visions communicated an average of 5.1 values. Thus, we can conclude that even hospital leaders who communicate visions with image-based words usually impair the establishment of a shared ultimate goal by conveying too many values. This predisposition toward too many values is generalizable to different contexts: in the same randomly selected sample of 30 Fortune 500 companies used for the analysis reported in the prior footnote, we found that companies included an average of 6 values per values statement. 
vision. Together, both actions provide a vague sense of purpose rather than a concrete and clear one.

We next sought to constructively replicate these results by demonstrating evidence of the mechanisms through which the interaction between vision imagery and the number of values impacts collective outcomes. To do this, we ran an experiment with full-time employees. This experiment adds to the archival data by establishing causality, ruling out alternative explanations, and directly testing the proximal effect of vision-based and values-based rhetoric on performance quality.

\section{STUDY 2: EXPERIMENT}

\section{Sample, Study Design, and Procedure}

186 full-time employees were recruited from an online database, Clearvoice, which allowed us to only select full-time employees. Participants ranged in age from 21 to 66 years, with a mean age of 43.5 years. Women constituted $63 \%$ of the sample. The study was a $2 \times 2$ design, whereby image-based words (small versus large number) was a between-subjects factor and values (small versus large number) was a within-subjects factor. The within-subjects factor was counter-balanced such that it was randomly determined whether the "small number of values" or "large number of values" condition would appear first. We ensured there were no order effects by testing for interactions between the experimental conditions and a factor that represented whether team members were exposed to the small or large number of values first. These interactions were not significant. In the instructions for the experiment, participants were told that they were going to perform the same task for two allied companies. The companies would thus have partial overlap in the messages their leaders use (in this case, the same vision and overlap in the content of the values, with the one shift being the number of values that were presented). Participants were randomly assigned to one of the two imagery conditions and then placed into virtual teams of 3 members each.

In line with the specialized nature of collectives in many organizations (Hollenbeck, Beersma, \& Schouten, 2012), members were given different responsibilities in the development 
of a new toy for a toy company. The first member focused on how the toy would be designed. $\mathrm{He} / \mathrm{she}$ was asked to write a description of the new toy design. The second member focused on how the design could be improved as well as the materials needed to develop a prototype of the design. This member was provided a set of materials as well as the cost for each material. He or she was then given a specific budget that he or she was told could not be exceeded. The third member then had the opportunity to improve the design further. All participants were told that it was important that their actions be congruent with the leader's statements regarding the vision and values of the company, which were presented at the same time (and separately from the task instructions) in the beginning of the task and then again once later in the task.

\section{Manipulation of Vision}

Participants were shown one of two visions. Both visions had the same cadence and sentence structure. To maintain realism, the number of words in each vision was set to be in line with the range of words in Fortune 500 company vision statements. To increase realism even more, the phrase with a large number of image-based words was modeled after two Fortune 500 company vision statements. The weak-imagery and strong-imagery visions were designed to vary only according to the number of image-based words (Guadagno et al., 2011) and not on any other dimensions. Specifically, we varied the three properties of language that drive perceptions of imagery (noted in the introduction). We held constant features of language that tie to specificity, including invariant hypernym (the objective level of words in categorization hierarchies) (Caraballo \& Charniak, 2001), the amount of detail (the number of words in both statements), and the identity of individuals and groups, according to manipulations of identifiability (Kogut \& Ritov, 2005). The two visions were as follows:

Weak imagery condition: "Our vision is that our toys - all of them made to perfection by our employees — will be enjoyed by all of our customers."

Strong imagery condition: "Our vision is that our toys - all of them crafted flawlessly by our workers—will make wide-eyed kids laugh and proud parents smile." 
To ensure that that both visions were different only in terms of imagery, we conducted a pre-test with twenty participants. ${ }^{12}$ The average age was 23.8 (40\% were women and $90 \%$ had work experience). We included three items from a scale by Guadagno et al. (2011) on image strength (e.g., "this vision statement gave me a clear mental image"). We included a three-item scale on specificity (e.g., "this vision statement is specific") (Locke \& Latham, 1990).

Additionally, we controlled for the perceived difficulty of attaining the vision statement with a three-item scale from Lied and Pritchard (1976). We measured prosocial impact with a four-item scale from Grant (2008). We measured perceived importance of the vision with a three-item scale (sample items include "the vision is important" and "the vision statement involves a grand purpose") (Vroom, 1964). We tested for whether participants believed that the vision resembled what they would encounter in a real organization with a three-item scale on message credibility (Flanagin \& Metzger, 2000). We tested for how well the vision held participants' attention with a three-item measure (adapted from Green \& Brock, 2000). Finally, we used the Gunning-Fog index to test for fluency (Shah \& Oppenheimer, 2007). When accounting for rater characteristics, the vision with a large number of image-based words yielded significantly more potent imagery in the minds of the pre-test participants than the vision with the small number of image-based words, $b=.287, p<.01$, whereas the conditions were not significantly different on any other factor. For completeness, we compared the two visions we used in the experiment to seven other similar variations. The two visions we used in the experiment were the only ones statistically different on perceived imagery while not different on any other factor. As described below, we replicated these pre-test results with manipulation checks used in the experiment.

\footnotetext{
${ }^{12}$ The weak imagery vision that was pre-tested had the terms "with excellence" and "people." For the experiment we changed these terms to "to perfection" and "employees," respectively, to make them semantically equivalent to the strong imagery statement, which had the terms "crafted flawlessly" and "workers." However, our experimental manipulation checks assess the two statements exactly as they appear in the text above. Thus, slightly more weight should be put on the post-experimental questionnaire manipulation checks (which we describe below) than the pretested statements, even though they provided results that were substantively identical.
} 


\section{Manipulation of Values}

We conveyed values-based rhetoric so it matched a speaking style in which a leader would introduce a value and then describe how it applies to the organization. To maximize external validity for the number of values we chose, we followed Chatman and Flynn's (2005) recommendations to turn to a naturally occurring setting. Thus, we referenced the archival data from Study 1, for which the average number of values in the hospitals' values statements rounded to 5 and the standard deviation rounded to 4 . Since one and nine represents about one standard deviation below and above the mean, respectively, we chose one value for the "small number of values" condition and nine values for the "large number of values" condition. For the conditions with nine values, we chose six of the values based on those reported by Hansen (2010) to be the six most popular values in values statements. Hansen did not list the seventh, eight, and ninth most popular values, therefore we chose these three values by comparing the list of values provided by O'Reilly et al. (1991) to the values from the archival data in study 1 . Of the values that overlapped between these two lists, we chose the three that appeared most often in the sample of hospitals.

The nine values and their descriptions were as follows: "Accountability—we make every product up to specifications and on time. Customer Satisfaction - to have one of our products means to have fun! Profitability—customers choose us first and choose us often. Integrity—we always stand by our principles in our dealings with co-workers and customers. Respect-we treat our customers and each other as we would want to be treated. Teamwork - together we can accomplish the unthinkable. Open Communication - we speak transparently and listen intently. Innovation - we are on the cutting-edge of the industry. Quality - our customers receive only the best-designed, best-built products."

In the two conditions with nine values, we displayed each value along with the brief description of what it means to the company. In the other two conditions, we displayed a single value along with the brief description of what it means to the company. To ensure that the content of the value in the single-value condition did not bias results, one value from the nine 
values listed above was randomly selected for each iteration of the one-value condition. Therefore, each participant in the one-value condition had the same odds of seeing any one of the nine values.

\section{Dependent Variable}

Two steps were needed to evaluate performance quality, which was the quality of the toy design. One of the study authors first evaluated the toy designs to determine which ones could not be built given the available materials. Seven children, ranging in age from 7 to 12 , were then asked to evaluate how much they would want to play with each toy. Children were chosen because they drive demand in this industry-parents and guardians are most likely to purchase toys that their children want to play with. The scale they used ranged from 0 (no value) to 100 (maximal value). Ideas for toys that could not be built were given a 0 since designers were clearly instructed to only articulate ideas that could be built with the available materials. Further, participants who did not provide a design idea were given a 0 . Examples of toys that received high scores were pliable magnets that can be used for building, and small, brightly colored paper birds that can be personalized and then launched by an inexpensive propulsion system so that they could fly across a room. Examples of toys that received low scores were a toy boat and a bookmark that could be folded into any shape. Inter-rater reliability, as measured with an intraclass correlation coefficient, was .611. Since causality requires that the cause precede the effect in time, we centered our analysis on final design ideas generated after coordination between the first and second members began. We employed a control variable to account for initial design ideas generated by the first team member. We note below how we conducted a variety of robustness checks to account for alternative ways of constructing and testing this measure.

\section{Mediators}

There were two mediators, both at the group level. The first was the extent to which the ultimate goal was shared. Participants were asked to describe their goals, including what they perceived as the ultimate purpose of the task, in open-ended dialogue boxes. This resulted in 12,337 words of codable text. We used a computer algorithm to calculate the amount of overlap 
among team members in their construal of the ultimate goal of the task. The algorithm was written so that a team was given one point when multiple members wrote down the same word or phrase related to the ultimate goal. Specifically, we coded for words that appeared in the leader's vision and values statements, since these were framed as representing the organization's ultimate goal. In line with our assumption that an ultimate goal is encoded in both concrete and conceptual terms, we added together concrete (vision-based) and conceptual (values-based) descriptions into a single variable. An example of a team with a strongly shared sense of purpose is a team in which all three members mentioned "profit" "profits," or "profitability" as a key aim of the task. Another example is a team in which each of the following goals were shared: (a) the importance of creating "quality" products, (b) the importance of capturing the interest of parents, and (c) the importance of children using and benefiting from the toys. Examples of teams with no shared sense of purpose were two in which the members recorded 60 words and 78 words, respectively, but possessed no overlap in their perceptions of the ultimate goal.

It is important to empirically distinguish the effects of a shared representation of the ultimate goal from the effects of a shared understanding of present task responsibilities and short-term goals (Cannon-Bowers et al., 1990). We thus wrote a second algorithm capturing the amount of overlap among team members with respect to their construal of the task and shortterm goals (e.g., "design toy," "buy materials"). To do this, we followed the protocol outlined in research on shared mental models related to the dimension of shared understanding of task content (Mohammed, Klimoski, \& Rentsch, 2000). For this variable, each team was given one point for each word or phrase shared amongst members related to how they perceived the task they were working on in the present.

The second mediator was coordination. Tasks that are more conjunctive and interdependent - that is, one member can only perform his or her role well if another member performs his or her role sufficiently well—require the most coordination (Frank \& Anderson, 1971). We thus shaped the role of the second member to be dependent on the first member. As noted above, the first member was told to develop an initial idea for a toy design, and the second 
member was assigned to choose materials to build the prototype of the toy. The first member was given certain specifications for articulating the toy design, including the types of materials that were available for building a prototype of the toy. The second member was then given a pool of materials and a set budget that he/she was instructed to not exceed when choosing materials for assembling a prototype of the toy design. The cost of each material was clearly labeled. In addition to providing the initial design idea, the first member was told that he/she should "provide an explanation of its appearance and functions" so that the second member could more easily choose materials for the toy design, leading to fewer errors, whereby errors were calculated as the amount that the budget exceeded the maximum allowed. Even if the toy could be built with available materials (which was taken into consideration above in the assessment of performance quality), the cost of materials could still exceed the specified budget.

We used error prevention as a measure for coordination because (1) it proxies how effectively the first member took the perspective of the second member when describing the toy design and (2) how well the second member used the instructions of the first member while taking operational constraints (cost of materials) into consideration. As further support for this measure, Weick and Roberts (1993) suggest that the omission of errors is an essential indicator of an effectively coordinated system. Based on his/her experience with choosing materials for assembling the toy, the second member had the opportunity to update the toy design for the third member of the team. The third member, who had the opportunity to update and then finalize the toy design in order to best position it for a target market, received information from the first two members after they performed their functions, leading the third member to be dependent on the actions of first two members.

\section{Results and Discussion}

In a post-experimental questionnaire, we used the same scales that we used in the pre-test to perform manipulation checks. As with the pre-test, participants reported that the leader's vision with a large number of image-based words triggered a stronger mental image than the leader's vision with a small number of image-based words, $F(1,184)=7.64, p<.01$. Also as 
with the pre-test, the visions were perceived to be the same on all other relevant dimensions, including specificity, importance, difficulty, and message credibility. In addition to including the control variable that accounted for how well individuals understood the task (described above), we conducted various sensitivity analyses to ensure that the content of the values did not affect the results ${ }^{13}$ and to rule out the possibility that participants perceived that one of the vision statements provided clearer task instructions than the other. ${ }^{14}$ The correlation between shared ultimate goal and coordination was .06; the correlation between shared ultimate goal and performance quality was .08; and the correlation between coordination and performance quality was .08.

We conducted an analysis of variance while accounting for the within-subjects variable with repeated measures. In support of Hypothesis 1, there was an interaction between vision imagery and the number of values on performance quality, $F(1,59)=7.31, p<.01$. This interaction held when including fixed effects representing coders. Probing simple effects, we found that the leader's expression of image-based words increased performance in the "one value" condition $(b=15.78, t=2.74, p<.01)$, but not in the "nine values" condition $(b=-3.23$, $t=-.55, n s)$. For Hypothesis $2,{ }^{15}$ we proposed that image-based words would increase the extent to which an ultimate goal is shared across members (Path A in Figure 1), a shared ultimate goal increases coordination, (Path B in Figure 1), and coordination improves performance quality (Path $\mathrm{C}$ in Figure 1). We also predicted that Paths A and B would be conditional on the number of values communicated by leaders.

\footnotetext{
${ }^{13}$ Among the sensitivity analyses that we conducted, we established that (1) all nine values were mentioned in tandem with both visions, suggesting that participants perceived that all nine values were consistent with both visions, and (2) value content did not moderate the effect of vision imagery within or between conditions. We thank a reviewer and the editor for this suggestion.

${ }^{14}$ Among the sensitivity analyses that we conducted, we established that (1) participants did not report in their responses to open-ended items that they followed narrower instructions for one vision relative to the other, and (2) toy ideas did not meet narrower criteria for one vision relative to the other.

${ }^{15}$ We had complete data for all variables except for coordination, as there were 12 instances when teams did not attempt to procure materials. Given that the majority of these instances (10) were in conditions in which we expected coordination to be harmed, excluding them from this analysis made our tests more conservative.
} 
We first tested this hypothesis in two steps consistent with procedures recommended by Hayes (2013), using the measure of shared mental models as a covariate. We tested whether both paths of the indirect effect of image-based words on coordination through a shared ultimate goal (i.e., image-based words $\rightarrow$ shared ultimate goal $\rightarrow$ coordination) were moderated by the number of values expressed by the leader. In support of this expectation, bootstrapping analyses demonstrated that $95 \%$ confidence intervals for the indirect effect (4.03) excluded zero when there was one value [95\% CI: .35, 14.73] but not when there were nine values. ${ }^{16} \mathrm{We}$ then needed to ensure that this moderating effect of values extended over the remainder of the indirect effect (i.e., shared ultimate goal $\rightarrow$ coordination $\rightarrow$ performance quality). Consistent with our theoretical model, we again tested whether Path B (shared ultimate goal $\rightarrow$ coordination) was conditional on the number of values. In support of this effect, bootstrapping analyses demonstrated that $95 \%$ confidence intervals for the indirect effect (.28) excluded zero when there was one value [95\% CI: .04, 1.03] but not when there were nine values. In addition to testing the same interaction in both analyses, we were able to interpret the two analyses together as a test of the overall theory by using the same random seed to determine the bootstrapping samples, thereby ensuring that the re-sampling procedure was identical for the estimates of confidence intervals in both analyses. ${ }^{17}$ Finally, we estimated a conditional indirect effect for the full model (image-based words $\rightarrow$ shared ultimate goal $\rightarrow$ coordination $\rightarrow$ performance quality),

\footnotetext{
${ }^{16}$ As supplementary analyses, we tested the interaction between vision and values on a shared ultimate goal, $F(1$, $60)=.02, n s$, and coordination, $F(1,54)=1.85$, ns. However, neither interaction needs to be significant for the $95 \%$ confidence interval for the conditional indirect effect to exclude zero (Hayes, 2013).

${ }^{17}$ We performed additional analyses to assess the robustness of how performance quality was constructed by altering the following parameters alone and in combination: employing two alternative versions of the dependent variable that included toy ideas that were close to meeting the specifications described above; employing two alternative versions of the dependent variable that excluded toy ideas that were close to not meeting the specifications described above; using robust standard errors; removing the control variable used to account for initial design ideas generated by the first team member (i.e., ideas generated before coordination occurred) from our test of Hypotheses 1 and 2; and removing the control variable that accounted for how well individuals understood the task from our test of Hypothesis 2. Since each of the alternative measures deviates from the optimal criteria used to construct each variable, these robustness checks represented conservative tests. All of these robustness checks for Hypothesis 1 were significant at $p<.05$, with the exception being one of the two versions of the dependent variable that included toy ideas that were close to meeting specifications; analyses using this version of the dependent variable were significant at $p<.10$. For all of the robustness checks for Hypothesis 2, bootstrapping analyses demonstrated that $95 \%$ confidence intervals for the indirect effects excluded zero when there was one value but not when there were nine values.
} 
whereby the number of values moderated the first two paths, by using bootstrapped estimates of coefficients in a path analysis. $95 \%$ confidence intervals for the full indirect effect (.09) excluded zero when there was one value [95\% CI: .001, .88] but not when there were nine values.

Overall, this experiment used data from four sources to (1) constructively replicate the interaction between image-based words and number of values on performance quality that we found in the archival study; (2) unpack the indirect effects that explained the relationship between image-based words and performance quality; and (3) uncover how the moderating effect of the number of values acts on this indirect pathway. These results also provided internal validity, a complement to the external validity demonstrated in study 1 .

\section{GENERAL DISCUSSION}

\section{Theoretical Contributions}

We provided support for a theory that links leader rhetoric about ultimate goals to follower cognition, follower behavior, and follower performance in a collective setting. Having done so, we advance understanding of the association between leadership and two separate topics: rhetoric and shared cognition.

Leadership and rhetoric. We introduced a new perspective on one of the foremost responsibilities of leaders: crafting rhetoric to convey the ultimate purpose of work (Hemphill \& Coons, 1957; Locke, 1999). Our efforts answered calls to study specific leader behaviors in order to better understand how leaders make an impact (Antonakis et al., 2003; van Knippenberg $\&$ Sitkin, 2013). Along these lines, we provided several insights. First, we demonstrated how and when visions and values determine not only the perception that employees are driven by a higher purpose, but also by a shared purpose. By reducing the traditional focus on cognition to a specific type of cognition (shared cognition), we found that visions and values only trigger a common purpose when combined in a particular way.

Another contribution of our study to research on leadership and rhetoric relates to the dimensions of visions and values that we isolated. Extensive research has focused on specific 
characteristics of visions and values (Awamleh \& Gardner, 1999; Baum, 1998; Conger, 1991; Den Hartog, 1997; Filion, 1991; Kirkpatrick \& Locke, 1996; Kirkpatrick, Wofford, \& Baum, 2002; Larwood, Falbe, Kriger, \& Miesing, 1995; Shamir et al., 1993; Strange \& Mumford, 2002), however we have focused on dimensions that are rarely studied yet still central to what make visions and values distinct from other forms of rhetoric. Although vision communication is widely studied and has been identified as the primary example of a specific behavior that leadership researchers should isolate (van Knippenberg and Sitkin, 2013: 46-48), prior to our study there had been no effort to study the collective or organizational consequences of the very property of language — image-based words - that distinguishes vision from other types of rhetoric (cf. Emrich et al., 2001). We provide a first look at these consequences. We also considered a key aspect of variability in how values are conveyed. Whereas prior research has focused on the general presence of values or the content of values (O'Reilly et al., 1991), we examined the number of values because it represents the number of discrete concepts that can be used to derive meaning. Taken together, these properties of visions and values are critical from the perspective of external validity, as our sample indicates that leaders typically impart a single vision that varies in terms of the number of image-based words and value systems that vary in number. In sum, we independently contributed to the literatures on visionary rhetoric and values-based rhetoric, both of which are stand-alone bodies of research in their own right.

As a final contribution to the literature on leadership and rhetoric, our exploratory analyses of the study 1 data uncovered a prescriptive-descriptive gap by demonstrating that the types of messages employees respond to best are those that leaders are least likely to craft. These results beg the following question: if performance is boosted by leader rhetoric comprised of image-laden words and four values or less, then why are leaders biased toward crafting rhetoric without vision imagery ${ }^{18}$ and with more than four values? One reason leaders tend to come up

\footnotetext{
${ }^{18}$ The results of studies 1 and 2 align to suggest that image-laden visions boost performance. But beyond performance, there are other reasons that leaders should use image-based words when crafting visions. A vision that is largely conceptual in nature taints the very purpose of a vision, which is to provide a verbal portrait of a future that organizational members can "see" (Rafferty \& Griffin, 2004). Indeed, the word "vision" explicitly mandates the usage of imagery since image-laden rhetoric is the form of language that lends visual detail (Emrich et al.,
} 
with concept-based visions rather than image-based visions may be that individuals think more abstractly as they project further into the future (Trope \& Liberman, 2003). Although message recipients are more stimulated by image-laden visions, message creators have a difficult time developing such messages. One reason for the bias toward articulating too many values may relate to issue selling (Howard-Grenville, 2007). As the conceptual formulation of an ultimate goal, a value represents a consequence of the achievement of short-term goals. Any potential consequence of an action can be highlighted as a rationale or a justification for undertaking that action. When attempting to gain an employee's commitment, leaders may sometimes be compelled to present as many reasons as possible for engaging in a task (i.e., more values).

Leadership and shared cognition. We advance research on the link between leader rhetoric, shared cognition, and collective action. We moved beyond the topic of how rhetoric can help shape a shared representation of past events (Weick, 1995) or a common representation of present reality (Cannon-Bowers et al., 1990) to how it can shape a shared representation of the future - in particular, the organization's long-term future, as represented by its ultimate goal. The limited work on how rhetoric influences the way employees think about the future (Gioia \& Chittipeddi, 1991) has not explored specific properties of rhetoric or shared cognition, much less the connection between them. Indeed, the question of how leaders craft a common understanding of the future - as central as this question is to the very notion of leadership - is not easily answered by extant theory. For instance, research that emphasizes the role of a shared purpose has not investigated how purpose comes to be shared in the first place (Kirkman \& Rosen, 1999). To remedy this oversight, we illuminated where a shared ultimate goal comes from and how it impacts performance. Further, by controlling for shared mental models (Cannon-Bowers et al., 1990), we demonstrated that a shared representation of an ultimate goal can boost coordination above and beyond a shared representation of the task. We also connected theory on collective mind (Weick \& Roberts, 1993), a form of shared cognition, with leader

2001). Along these lines, image-based words are not only what make a vision visionary, but also what differentiate a vision from other rhetorical mechanisms that represent ultimate goals - especially values. 
rhetoric. Since the key way that leaders navigate the sensegiving process is by using rhetoric, the connection we have established between rhetoric and collective mind provides a linking pin for two topics - sensegiving (Gioia \& Chittipeddi, 1991) and collective mind - that have otherwise remained disconnected.

Finally, our discovery that values moderate two distinct causal pathways - both the immediate antecedents and the immediate consequences of a shared ultimate goal (see Figure 1) - suggests that the number of values not only plays a critical role in initially shaping a common sense of purpose (the path from leader rhetoric to follower shared cognition in Figure 1), but also serves as a coordinating mechanism. When leaders express a small number of values, employees have a more focused set of principles they can use to guide their behavior during implementation (the path from follower shared cognition to coordination in Figure 1). This refines the notion that values can be useful both when they are espoused (as ways to infuse image-based words with meaning) and enacted (as standards that guide behavior during task implementation), adding nuance to research that has suggested that organizational culture- $-a$ shared schema about how individuals should act according to the end-states that employees should aspire to achieve-is influenced by how values are communicated (Schein, 1990). Moreover, the number of core values may be a key proxy for the strength of the organization's culture, with a limited number of core values reflecting a strong culture with very clear expectations for how employees should act.

\section{Limitations and Future Directions}

There are several limitations of this research. First, study 1 may be missing key variables. For instance, we did not include proxies of the objective abilities of leaders and employees, which may influence rhetoric and performance. Second, we did not provide data on explanatory mechanisms in study 1 . Although we conducted the experiment to illuminate these mechanisms, it is unclear whether shared purpose and coordination explain the effect on readmission prevention in study 1 . This limitation may be especially pertinent to our robustness check (return on assets), which is less clearly affected by intergroup mechanisms and 
interpersonal interaction than heart attack readmission prevention. Third, study 1 relies on the coding of individual words, however other insights may be gained from coding different units, such as phrases, which capture how words work together to influence the formation of mental images. Fourth, in study 2 it is possible that the experiment manipulated other variables, including intensity of emotion (e.g., "laugh" may represent a higher arousal emotion than "enjoy"). Fifth, although we checked whether the content of the values aligned with the content of the vision for a subsample of hospitals, there is likely to be important variation in the extent to which the content of both messages is aligned. Future research should examine this link as an important boundary condition. ${ }^{19}$ Sixth, this research only focused on leader rhetoric-however, many other factors are likely to influence shared purpose and coordination, including role modeling, decisions about hiring, rewards, promotions, and other leader behaviors. Finally, we did not examine other characteristics of leader rhetoric that may be important, such as cadence, rhythm, and delivery style.

These limitations suggest many promising areas of future research. For instance, scholars could examine individual level pathways that may help to explain the effects of leader rhetoric on organizational performance. There are also likely to be a number of key boundary conditions of our findings. For instance, it is possible that a large number of values would not be problematic if the values are clearly prioritized (e.g., a leader communicates many values yet emphasizes only one as its core value). The extent to which leaders communicate visions and values at the same time (e.g., within the same sentence) may also be an important consideration. Finally, researchers should examine behavioral "nudges" or "repairs" that can help mitigate the bias toward communicating too little imagery and too many values.

\section{Managerial Implications}

One strength of this paper is the straightforward practical application of the findings. Our results suggest that, when speaking about the organization's ultimate goals, leaders should

\footnotetext{
${ }^{19}$ We thank a reviewer for this suggestion.
} 
express image-based words in tandem with four values or fewer. Further, our identification of the properties of language that trigger mental images (i.e., familiar objects with physical features and familiar, observable actions) should be particularly useful for managers who are interested in crafting more vivid visions. To encourage the use of this type of language, leaders can conjure an event that can be witnessed and then celebrated—perhaps even repeatedly (e.g., "putting a smile on parents' faces" is an event that can be observed on a recurring basis) (Heath \& Heath, 2008). Such a corrective action can move leaders away from deriving abstractions that will never materialize. Leaders could also be encouraged to focus on the experience of using their products or services. For instance, Russ Angold, co-founder of Ekso, a maker of wearable robot suits that allow paralyzed people to walk, frequently speaks in terms of vivid portrayals of experiences that his customers will have in the future. He has helped Ekso develop several visions with image-based words (e.g., "one day robotic exoskeletons [will] be a viable and accessible option for the millions of wheelchair users who [want] the option to stand up and walk") (eksobionics.com, 2005). Finally, it may even be the case that leaders can communicate images most effectively without using rhetoric at all—perhaps by using videos that depict a possible future.

Similar types of repairs can also be used to help leaders communicate fewer values. In line with the notion that leaders should strip away all information that is not essential to defining the organization's identity, leaders can be encouraged to articulate the single value that distinguishes their organization from others. Some companies, including Curtiss-Wright Controls Avionics \& Electronics, Browz, and DSM explicitly note that they are guided by a single value. For instance, DSM states that its operations are driven "by our core value that everything we do should contribute to a more sustainable world." As a way to winnow down an expressed values system, leaders can submit any given value to the following test: if we no longer communicated this value, would we retain — or perhaps enhance-our distinctive identity? 


\section{CONCLUSION}

Organizing and leading both involve directing collective action toward a purpose.

Rhetoric is a key medium through which leaders influence followers to understand this purpose. In this way, rhetoric can have a profound impact. But for its potential to be fulfilled, rhetoric cannot merely establish a sense of purpose. Rather, it must establish a shared sense of purpose. Through theory on leadership, rhetoric, and shared cognition, our research used multiple methods to demonstrate when and why leader expressions of visions and values trigger employees to experience a shared sense of the organization's ultimate goal, thereby boosting coordination and performance. Despite our findings, we discovered the unfortunate trend that leaders tend to craft visions with concepts as opposed to image-based words and to communicate a proliferation of values rather than a focused set of values - rhetorical patterns that undermine the establishment of a shared purpose. Thus, despite the widespread attention given to the importance of a shared purpose, it is the rare leader who successfully establishes it. 


\section{REFERENCES}

Antonakis, J., Avolio, B. J., \& Sivasubramaniam, N. 2003. Context and leadership: an examination of the nine-factor full-range leadership theory using the Multifactor Leadership Questionnaire. The Leadership Quarterly, 14(3): 261-295.

Awamleh, R., \& Gardner, W. L. 1999. Perceptions of leader charisma and effectiveness: The effects of vision content, delivery, and organizational performance. Leadership Quarterly, 10(3): 345-373.

Bass, B. M., \& Avolio, B. J. 1994. Improving organizational effectiveness through transformational leadership. Thousand Oaks, CA Sage.

Baum, J. R. 1998. A longitudinal study of the relation of vision and vision communication to venture growth in entrepreneurial firms. Journal of Applied Psychology, 83(1): 43-54.

Bazzoli, G. J., Shortell, S. M., Dubbs, N., Chan, B., \& Kralovec, P. 1999. A taxonomy of health networks and systems: Bringing order out of chaos. Health Services Research, 33(6).

Benbassat, J., \& Taragin, M. 2000. Hospital readmissions as a measure of quality of health care: advantages and limitations. Archives of Internal Medicine, 160(8): 1074.

Besson, G., Ceccaldi, M., Didic, M., \& Barbeau, E. J. 2012. The speed of visual recognition memory. Visual Cognition, 20(10): 1131-1152.

Blau, P., \& Scott, W. 1962. Formal organizations: A comparative approach: Stanford Business Books.

Bollen, K. A., \& Jackman, R. W. 1985. Regression diagnostics an expository treatment of outliers and influential cases. Sociological Methods \& Research, 13(4): 510-542.

Brown, M. E., \& Trevino, L. K. 2006. Socialized Charismatic Leadership, Values Congruence, and Deviance in Work Groups. Journal of Applied Psychology, 91(4): 954-962.

Campbell, D. T., \& Fiske, D. W. 1959. Convergent and discriminant validation by the multitraitmultimethod matrix. Psychological Bulletin, 56(2): 81-105.

Cannon-Bowers, J. A., Salas, E., \& Converse, S. A. 1990. Cognitive psychology and team training: Shared mental models in complex systems. Human Factors Society, 33: 1-4. 
Caraballo, S. A., \& Charniak, E. 2001. Automatic construction of a hypernym-labeled noun hierarchy from text: Brown University.

Chatman, J. A. 1989. Improving Interactional Organizational Research: A Model of PersonOrganization Fit. The Academy of Management review, 14(3): 333-349.

Chatman, J. A., \& Flynn, F. J. 2005. Full-cycle micro-organizational behavior research. Organization Science, 16(4): 434-447.

Chatterjee, A., \& Hambrick, D. C. 2007. It's all about me: Narcissistic chief executive officers and their effects on company strategy and performance. Administrative Science Quarterly, 52(3): 351-386.

Clark, J. R., \& Huckman, R. S. 2012. Broadening focus: Spillovers, complementarities, and specialization in the hospital industry. Management Science, 58(4): 708-722.

Collins, J. C., \& Porras, J. I. 1994. Built to last. New York: Harper Collins.

Conger, J. A. 1991. Inspiring others: The language of leadership. The Executive, 5(1): 31-45.

Conger, J. A., \& Kanungo, R. N. 1987. Toward a behavioral theory of charismatic leadership in organizational settings. Academy of Management Review, 12(4): 637-647.

Cooper, G. S., Sirio, C. A., Rotondi, A. J., Shepardson, L. B., \& Rosenthal, G. E. 1999. Are readmissions to the intensive care unit a useful measure of hospital performance? Medical care, 37(4): 399-408.

Cropanzano, R., James, K., \& Citera, M. A. 1993. A goal hierarchy model of personality, motivation, and leadership. Research in Organizational Behavior, 15: 267-322.

Cyert, R. M., \& March, J. G. 1963. A Behavioral Theory of the Firm. Englewood-Cliffs, New Jersey: Prentice-Hall.

de Groot, A. M. 1989. Representational aspects of word imageability and word frequency as assessed through word association. Journal of Experimental Psychology: Learning, Memory, and Cognition, 15(5): 824.

Den Hartog, D. N. 1997. Charisma and rhetoric: Communicative techniques of international business leaders. The Leadership Quarterly, 8(4): 355. 
Denison, D. R., \& Spreitzer, G. M. 1991. Organizational culture and organizational development: A competing values approach. Research in Organizational Change and Development, 5(1): 1-21.

Dougherty, D. 1992. Interpretive barriers to successful product innovation in large firms. Organizational Science, 3(2): 179-202.

Edwards, J. R. 2008. To prosper, organizational psychology should... overcome methodological barriers to progress. Journal of Organizational Behavior, 29(4): 469-491.

Emrich, C. G., Brower, H. H., Feldman, J. M., \& Garland, H. 2001. Images in words: Presidential rhetoric, charisma, and greatness. Administrative Science Quarterly, 46(3): 527-557.

Ensley, M. D., \& Pearce, C. L. 2001. Shared cognition in top management teams: Implications for new venture performance. Journal of Organizational Behavior, 22(2): 145-160.

Epstein, S. 1998. Cognitive-experiential self-theory, Advanced Personality: 211-238: Springer.

Filion, L. J. 1991. Vision and relations: Elements for an entrepreneurial metamodel. International Small Business Journal, 9(2): 26-40.

Flanagin, A. J., \& Metzger, M. J. 2000. Perceptions of Internet information credibility. Journalism \& Mass Communication Quarterly, 77(3): 515-540.

Fleishman, E. A., \& Peters, D. R. 1962. Interpersonal values, leadership attitudes, and managerial "success". Personnel Psychology, 15(2): 127-143.

Frank, F., \& Anderson, L. R. 1971. Effects of task and group size upon group productivity and member satisfaction. Sociometry: 135-149.

Fu, P. P., Tsui, A. S., Liu, J., \& Li, L. 2010. Pursuit of whose happiness? Executive leaders' transformational behaviors and personal values. Administrative Science Quarterly, 55(2): 222-254.

Fussell, S. R., \& Krauss, R. M. 1989. The effects of intended audience on message production and comprehension: Reference in a common ground framework. Journal of Experimental Social Psychology, 25(3): 203-219.

Gioia, D. A., \& Chittipeddi, K. 1991. Sensemaking and sensegiving in strategic change initiation. Strategic management journal, 12(6): 433-448. 
Gittell, J. H. 2002. Coordinating mechanisms in care provider groups: Relational coordination as a mediator and input uncertainty as a moderator of performance effects. Management Science, 48(11): 1408-1426.

Grant, A. M. 2008. Does intrinsic motivation fuel the prosocial fire? Motivational synergy in predicting persistence, performance, and productivity. Journal of Applied Psychology, 93(1): 48-58.

Grant, A. M. 2012. Leading with meaning: Beneficiary contact, prosocial impact, and the performance effects of transformational leadership Academy of Management Journal, $55(2)$.

Green, M. C., \& Brock, T. C. 2000. The role of transportation in the persuasiveness of public narratives. Journal of Personality and Social Psychology, 79: 701-721.

Greenwald, L., Cromwell, J., Adamache, W., Bernard, S., Drozd, E., Root, E., \& Devers, K. 2006. Specialty versus community hospitals: referrals, quality, and community benefits. Health Affairs, 25(1): 106-118.

Gruys, M. L., Stewart, S. M., Goodstein, J., Bing, M. N., \& Wicks, A. C. 2008. Values enactment in organizations: A multi-level examination. Journal of Management, 34(4): 806-843.

Guadagno, R. E., Rhoads, K. v. L., \& Sagarin, B. J. 2011. Figural vividness and persuasion: Capturing the "elusive" vividness effect. Personality and Social Psychology Bulletin, 37(5): 626-638.

Gunning, R. 1968. The fog index after twenty years. Journal of Business Communication, 6: 313.

Hackman, R. 1987. The design of work teams. In J. Lorsch (Ed.), Handbook of Organizational Behavior. Englewood Cliffs, NJ: Prentice-Hall.

Hale, C. 2012. Make-or-Break Verbs, The New York Times. New York, NY.

Hambrick, D. C., \& Mason, P. A. 1984. Upper echelons: The organization as a reflection of its top managers. Academy of Management Review: 193-206.

Hansen, E. G. 2010. Responsible leadership systems: An empirical anlaysis of integrating corporate responsibility into leadership systems: Gabler Verlag. 
Harackiewicz, J. M., \& Elliot, A. J. 1998. The joint effects of target and purpose goals on intrinsic motivation: A mediational analysis. Personality and Social Psychology Bulletin, 24: 675.

Hartnell, C., \& Walumbwa, F. 2010. Transformational leadership and organizational culture. The Handbook of Organizational Culture and Climate: 225.

Hayes, A. F. 2013. Introduction to mediation, moderation, and conditional process analysis: $A$ regression-based approach: Guilford Press.

Heath, C., \& Heath, D. 2008. Made to Stick: Why some ideas take hold and others come unstuck: Arrow Books.

Hemphill, J. K., \& Coons, A. E. 1957. Development of the leader behavior description questionnaire. In R. M. Stodgill, \& A. E. Coons (Eds.), Leader behavior: Its description and measurement: 6-38. Columbus, Ohio: Bureau of Business Research, Ohio State University.

Hoffmann, J., Denis, M., \& Ziessler, M. 1983. Figurative features and the construction of visual images. Psychological Research, 45(1): 39-54.

Hollenbeck, J. R., Beersma, B., \& Schouten, M. E. 2012. Beyond team types and taxonomies: A dimensional scaling conceptualization for team description. Academy of Management Review, 37(1): 82-106.

Howard-Grenville, J. A. 2007. Developing issue-selling effectiveness over time: Issue selling as resourcing. Organization Science, 18(4): 560-577.

Kirkman, B. L., \& Rosen, B. 1999. Beyond self-management: Antecedents and consequences of team empowerment. academy of Management Journal, 42(1): 58-74.

Kirkpatrick, S. A., \& Locke, E. A. 1996. Direct and indirect effects of three core charismatic leadership components on performance and attitudes. Journal of Applied Psychology, 81(1): 36-51.

Kirkpatrick, S. A., Wofford, J. C., \& Baum, J. R. 2002. Measuring motive imagery contained in the vision statement. The Leadership Quarterly, 13(2): 139-150.

Kogut, T., \& Ritov, I. 2005. The singularity effect of identified victims in separate and joint evaluations. Organizational behavior and human decision processes, 97(2): 106-116. 
Kotter, J. P. 1996. Leading change. Cambridge, MA: Harvard Business School Press.

Kroll, J. F., \& Merves, J. S. 1986. Lexical access for concrete and abstract words. Journal of Experimental Psychology: Learning, Memory, and Cognition, 12(1): 92.

Landon, B. E., Normand, S.-L. T., Lessler, A., O'Malley, A. J., Schmaltz, S., Loeb, J. M., \& McNeil, B. J. 2006. Quality of care for the treatment of acute medical conditions in US hospitals. Archives of Internal Medicine, 166(22): 2511.

Larwood, L., Falbe, C. M., Kriger, M. P., \& Miesing, P. 1995. Structure and meaning of organizational vision. Academy of Management Journal, 38(3): 740-769.

Liberman, N., \& Förster, J. 2009. Distancing from experienced self: how global-versus-local perception affects estimation of psychological distance. Journal of Personality and Social Psychology, 97(2): 203.

Lied, T. R., \& Pritchard, R. D. 1976. Relationships between personality variables and components of the expectancy-valence model. Journal of Applied Psychology, 61(4): 463-467.

Locke, E. A. 1999. The essence of leadership: The four keys to leading successfully. New York: Lexington.

Locke, E. A., \& Latham, G. P. 1990. A theory of goal setting and task performance. Englewood Cliffs, NJ: Prentice-Hall.

Lord, R. G., \& Brown, D. J. 2001. Leadership, values, and subordinate self-concepts. The Leadership Quarterly, 12(2): 133-152.

Lucas, S. E., \& Medhurst, M. J. 1999. Words of a century: the top 100 american speeches, 1900-1999 Oxford University Press.

McGahan, A. M., \& Porter, M. E. 2002. What do we know about variance in accounting profitability? Management Science, 48(7): 834-851.

Mohammed, S., Klimoski, R., \& Rentsch, J. R. 2000. The measurement of team mental models: We have no shared schema. Organizational Research Methods, 3(2): 123-165.

Nemanich, L. A., \& Keller, R. T. 2007. Transformational leadership in an acquisition: A field study of employees. The Leadership Quarterly, 18(1): 49-68. 
Nisbett, R., \& Ross, L. 1980. Human inference: Strategies and shortcomings of social judgment. Englewood Cliffs, N.J.: Prentice-Hall.

O'Reilly, C. A., Chatman, J., \& Caldwell, D. F. 1991. People and organizational culture: A profile comparison approach to assessing person-organization fit. Academy of Management Journal, 34(3): 487-516.

Ocasio, W. 1998. Towards an attention-based view of the firm. Strategic Management Journal, 18(S1): 187-206.

Parsons, T. 1956. Suggestions for a sociological approach to the theory of organizations. Administrative Science Quarterly, 1(1): 63-85.

Pearce, C. L., \& Ensley, M. D. 2004. A reciprocal and longitudinal investigation of the innovation process: The central role of shared vision in product and process innovation teams (PPITs). Journal of Organizational Behavior, 25(2): 259-278.

Peikes, D. N., Moreno, L., \& Orzol, S. M. 2008. Propensity Score Matching. The American Statistician, 62(3): 222-231.

Raes, A. M., Heijltjes, M. G., Glunk, U., \& Roe, R. A. 2011. The interface of the top management team and middle managers: A process model. Academy of Management Review, 36(1): 102-126.

Rafferty, A. E., \& Griffin, M. A. 2004. Dimensions of transformational leadership: Conceptual and empirical extensions. The Leadership Quarterly, 15(3): 329.

Rokeach, M. 1973. The nature of human values. New York: Free Press.

Rowden, R. W. 2000. The relationship between charismatic leadership behaviors and organizational commitment. Leadership \& Organization Development Journal, 21(1): 30-35.

Russell, R. F. 2001. The role of values in servant leadership. Leadership \& Organization Development Journal, 22(2): 76-84.

Schein, E. H. 1990. Organizational culture. American psychologist, 45(2): 109.

Schuh, A. M., \& Miller, G. M. 2006. Maybe Wilson was right: Espoused values and their relationship to enacted values. Intl Journal of Public Administration, 29(9): 719-741. 
Schwartz, S. H. 1992. Universals in the content and structure of values: Theoretical advances and empirical tests in 20 countries. Advances in experimental social psychology, 25(1): 1-65.

Senge, P. M., \& Sterman, J. D. 1992. Systems thinking and organizational learning: Acting locally and thinking globally in the organization of the future. European Journal of Operational Research, 59(1): 137-150.

Shah, A. K., \& Oppenheimer, D. M. 2007. Easy does it: The role of fluency in cue weighting. Judgment and decision making, 2(6): 371.

Shamir, B., House, R. J., \& Arthur, M. B. 1993. The motivational effects of charismatic leadership: A self-concept based theory Organization Science, 4(4): 577-594.

Song, Y., Tian, M., \& Liu, J. 2012. Top-down processing of symbolic meanings modulates the visual word form area. The Journal of Neuroscience, 32(35): 12277-12283.

Spencer, B. A. 1994. Models of organization and total quality management: a comparison and critical evaluation. Academy of Management Review, 19(3): 446-471.

Stam, D. A., van Knippenberg, D., \& Wisse, B. 2010. The role of regulatory fit in visionary leadership. Journal of Organizational Behavior, 31(4): 499-518.

Strange, J. M., \& Mumford, M. D. 2002. The origins of vision: Charismatic versus ideological leadership The Leadership Quarterly 13(4): 343-377.

Thompson, L., \& Fine, G. A. 1999. Socially shared cognition, affect, and behavior: A review and integration. Personality and Social Psychology Review, 3(4): 278-302.

Trope, Y., \& Liberman, N. 2003. Temporal construal. Psychological Review, 110(3): 403-421.

Tsai, W., \& Ghoshal, S. 1998. Social capital and value creation: The role of intrafirm networks. Academy of management Journal, 41(4): 464-476.

Tushman, M. L., \& Scanlan, T. J. 1981. Boundary spanning individuals: Their role in information transfer and their antecedents. Academy of Management Journal, 24(2): 289-305.

Van de Ven, A. H., Delbecq, A. L., \& Koenig Jr, R. 1976. Determinants of coordination modes within organizations. American Sociological Review: 322-338. 
van Knippenberg, D., \& Sitkin, S. B. 2013. A Critical Assessment of CharismaticTransformational Leadership Research: Back to the Drawing Board? The Academy of Management Annals, 7(1): 1-60.

Venus, M., Stam, D., \& van Knippenberg, D. 2013. Leader emotion as a catalyst of effective leader communication of visions, value-laden messages, and goals. Organizational Behavior and Human Decision Processes, 122(1): 53-68.

Vroom, V. H. 1964. Motivation and work. New York: Wiley.

Wakslak, C. J., Trope, Y., Liberman, N., \& Alony, R. 2006. Seeing the forest when entry is unlikely: probability and the mental representation of events. Journal of Experimental Psychology: General, 135(4): 641.

Waldman, D. A., \& Yammarino, F. J. 1999. CEO charismatic leadership: Levels-ofmanagement and levels-of-analysis effects. Academy of Management Review: 266-285.

Weick, K. 1995. Sensemaking in organizations. Thousand Oaks, CA: Sage Publications.

Weick, K. E., \& Roberts, K. H. 1993. Collective mind in organizations: Heedful interrelating on flight decks. Administrative science quarterly: 357-381.

Weick, K. E., Sutcliffe, K. M., \& Obstfeld, D. 2005. Organizing and the process of sensemaking. Organization science, 16(4): 409-421.

Whittington, J. L., Goodwin, V. L., \& Murray, B. 2004. Transformational leadership, goal difficulty, and job design: independent and interactive effects on employee outcomes. The Leadership Quarterly, 15(5): 593-606.

Wiener, Y. 1988. Forms of value systems: Focus on organizational effectiveness and cultural change and maintenance. Academy of Management Review, 13(4): 534-545.

Wooldridge, J. M. 2001. Econometric analysis of cross section and panel data: MIT press. Yukl, G. A. 1998. Leadership in organizations (4th ed.). Englewood Cliffs, NJ: Prentice Hall. 
FIGURE 1

Theoretical Model: The Influence of Leader Rhetoric about Ultimate Goals on Performance Quality

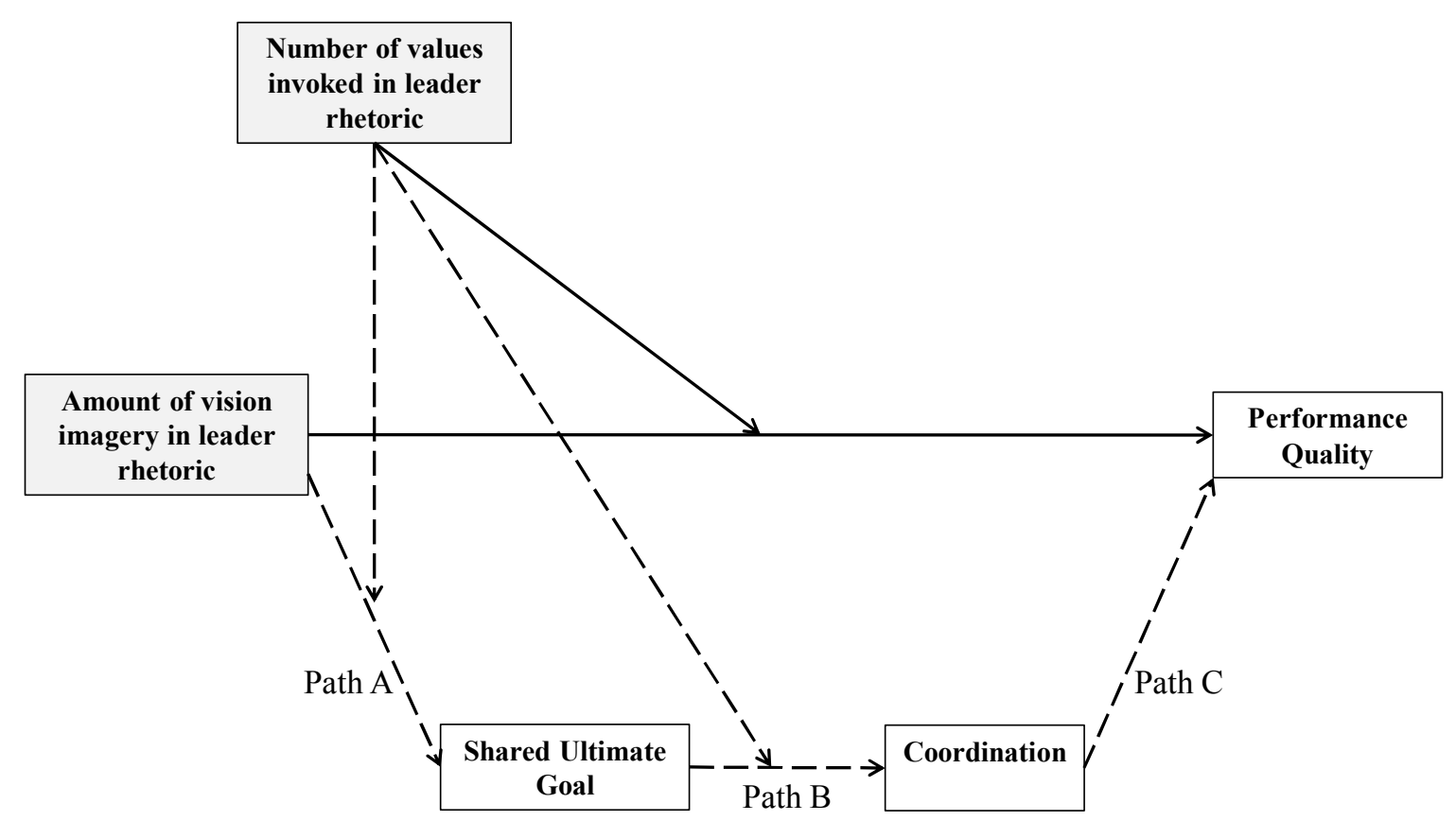

a. Solid lines represent the interaction between vision imagery and values-laden rhetoric on performance quality (Hypothesis 1). Dashed lines represent the conditional indirect effect (Hypothesis 2). 
a. The simple slope is significant at $p<.01$ for "small number of values" (1 value) and not significant for "large number of values" (7 values). Although "7 values" was chosen here for the "large number of values" interval, the simple slope is also not significant at other intervals, including 5 values and 9 values.

\section{FIGURE 2}

Interaction between Vision and Values in Study 1

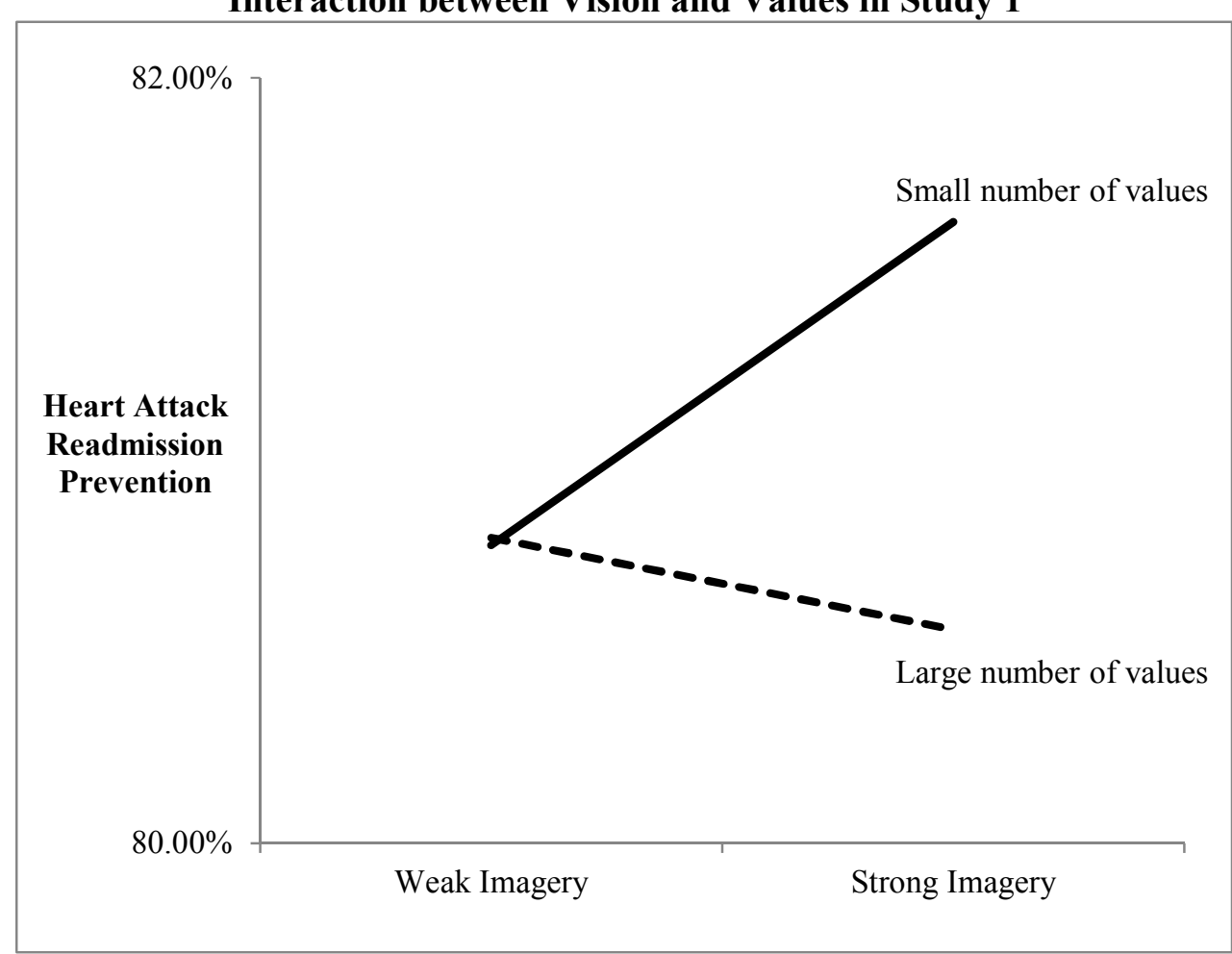


TABLE 1

Archival Study: Summary Statistics and Correlations

\begin{tabular}{|c|c|c|c|c|c|c|c|c|c|c|c|c|c|c|c|c|c|c|c|c|c|c|c|c|c|}
\hline & Mean & SD & Min & Max & 1 & 2 & 3 & 4 & 5 & 6 & 7 & 8 & 9 & 10 & 11 & 12 & 13 & 14 & 15 & 16 & 17 & 18 & 19 & 20 & 21 \\
\hline 1. HA Readmit Prevent 2010 & 80.24 & 1.41 & 76.80 & 84.60 & & & & & & & & & & & & & & & & & & & & & \\
\hline 2. HA Readmit Prevent 2009 & 80.49 & 1.17 & 77.70 & 83.40 & 0.65 & & & & & & & & & & & & & & & & & & & & \\
\hline 3. ROA 2010 & 0.06 & 0.08 & -0.29 & 0.22 & -0.08 & 0.09 & & & & & & & & & & & & & & & & & & & \\
\hline 4. ROA 2009 & 0.04 & 0.08 & -0.18 & 0.30 & -0.04 & 0.12 & 0.50 & & & & & & & & & & & & & & & & & & \\
\hline 5. Imagery & 11.06 & 24.27 & 1.00 & 230.00 & 0.21 & 0.25 & 0.00 & -0.01 & & & & & & & & & & & & & & & & & \\
\hline 6. Number of Values & 4.52 & 3.80 & 0.00 & 27.00 & 0.02 & -0.06 & 0.09 & 0.07 & 0.04 & & & & & & & & & & & & & & & & \\
\hline 7. Specialization & 0.28 & 0.10 & 0.14 & 0.55 & 0.00 & 0.02 & 0.09 & 0.06 & -0.01 & -0.12 & & & & & & & & & & & & & & & \\
\hline 8. US News & 0.23 & 0.42 & 0.00 & 1.00 & 0.01 & 0.09 & 0.17 & 0.19 & 0.03 & 0.17 & -0.04 & & & & & & & & & & & & & & \\
\hline 9. Magnet & 0.08 & 0.27 & 0.00 & 1.00 & 0.18 & 0.16 & 0.00 & 0.00 & -0.04 & 0.08 & -0.04 & 0.43 & & & & & & & & & & & & & \\
\hline 10. CEO Tenure & 4.85 & 3.30 & 0.00 & 9.00 & 0.20 & 0.19 & 0.09 & 0.18 & 0.19 & -0.16 & 0.22 & 0.21 & 0.05 & & & & & & & & & & & & \\
\hline 11. Hospital Size & 12,328 & 8,400 & 1,092 & 48,735 & 0.23 & 0.09 & -0.18 & -0.13 & 0.05 & 0.14 & -0.10 & 0.34 & 0.38 & 0.05 & & & & & & & & & & & \\
\hline 12. Competition (HHI) & 0.16 & 0.13 & 0.04 & 0.52 & 0.38 & 0.42 & 0.04 & 0.01 & 0.20 & -0.08 & -0.11 & -0.20 & -0.09 & 0.11 & -0.21 & & & & & & & & & & \\
\hline 13. System Membership & 0.54 & 0.50 & 0.00 & 1.00 & 0.10 & 0.12 & 0.01 & -0.11 & -0.09 & 0.11 & -0.14 & 0.03 & -0.15 & -0.07 & 0.09 & 0.30 & & & & & & & & & \\
\hline 14. Private Ownership & 0.85 & 0.36 & 0.00 & 1.00 & -0.05 & 0.09 & 0.23 & 0.12 & 0.08 & 0.13 & 0.05 & 0.23 & 0.01 & 0.17 & -0.10 & 0.04 & 0.04 & & & & & & & & \\
\hline 15. Medicaid & 0.20 & 0.12 & 0.01 & 0.57 & -0.12 & -0.39 & -0.06 & -0.13 & -0.19 & -0.13 & 0.40 & -0.16 & -0.20 & -0.07 & 0.14 & -0.22 & -0.05 & -0.32 & & & & & & & \\
\hline 16. Teaching & 0.06 & 0.18 & 0.00 & 1.20 & 0.01 & -0.19 & -0.26 & -0.14 & -0.04 & -0.06 & -0.19 & 0.04 & 0.01 & 0.01 & 0.49 & -0.21 & 0.18 & -0.30 & 0.31 & & & & & & \\
\hline 17. Tech Index & 2.84 & 1.34 & 0.00 & 6.06 & 0.36 & 0.23 & -0.06 & -0.01 & -0.02 & 0.16 & -0.20 & 0.27 & 0.27 & 0.12 & 0.64 & -0.02 & 0.21 & -0.09 & 0.07 & 0.30 & & & & & \\
\hline 18. Difficulty & 49.27 & 4.10 & 40.00 & 60.00 & -0.11 & -0.06 & 0.16 & 0.06 & 0.06 & 0.00 & -0.02 & 0.16 & 0.05 & 0.17 & 0.09 & -0.08 & 0.02 & 0.05 & 0.06 & 0.01 & 0.18 & & & & \\
\hline 19. Importance & 52.49 & 4.57 & 40.00 & 62.00 & 0.06 & -0.04 & 0.03 & 0.10 & 0.14 & 0.08 & -0.21 & 0.15 & 0.07 & 0.17 & 0.07 & 0.05 & -0.01 & 0.00 & -0.05 & -0.09 & 0.16 & 0.31 & & & \\
\hline 20. Categorical Specificity & 28.53 & 12.33 & 5.00 & 70.00 & 0.07 & 0.26 & 0.19 & 0.15 & 0.49 & -0.06 & 0.11 & 0.14 & 0.03 & 0.17 & -0.01 & 0.23 & 0.02 & 0.13 & -0.16 & -0.10 & 0.03 & 0.08 & 0.24 & & \\
\hline 21. Prosocial Value & 4.67 & 2.18 & 0.00 & 6.00 & 0.08 & 0.20 & 0.10 & 0.10 & 0.10 & -0.07 & -0.06 & 0.09 & 0.10 & 0.09 & -0.03 & 0.14 & 0.06 & -0.06 & -0.03 & 0.07 & 0.14 & 0.04 & 0.24 & 0.22 & \\
\hline 22. Gunning-Fog & 20.28 & 8.06 & 3.20 & 76.50 & 0.00 & 0.09 & -0.01 & 0.15 & -0.06 & 0.14 & -0.06 & 0.30 & 0.34 & 0.04 & 0.48 & -0.17 & -0.01 & 0.01 & -0.12 & 0.21 & 0.33 & 0.03 & 0.20 & 0.17 & 0.13 \\
\hline
\end{tabular}


TABLE 2

Archival Study: Regression Results

\begin{tabular}{|c|c|c|c|c|}
\hline Variables & $\begin{array}{c}(1) \\
\text { HA Readmission } \\
\text { Prevention }^{\mathrm{a}}\end{array}$ & $\begin{array}{c}(2) \\
\text { HA Readmission } \\
\text { Prevention }^{\mathrm{a}}\end{array}$ & $\begin{array}{c}(3) \\
\text { HA Readmission } \\
\text { Prevention }^{\mathrm{a}}\end{array}$ & $\begin{array}{c}\text { (4) } \\
\text { Return on } \\
\text { Assets }^{\mathrm{a}}\end{array}$ \\
\hline Image-based words in vision $^{b}$ & & $\begin{array}{c}0.00574 \\
(0.00383)\end{array}$ & $\begin{array}{l}0.0133^{* *} \\
(0.00369)\end{array}$ & $\begin{array}{l}0.000837^{*} \\
(0.000398)\end{array}$ \\
\hline Number of Values ${ }^{b}$ & & $\begin{array}{c}0.0244 \\
(0.0260)\end{array}$ & $\begin{array}{l}0.00320 \\
(0.0246)\end{array}$ & $\begin{array}{l}-0.00121 \\
(0.00227)\end{array}$ \\
\hline Image-based words $\mathrm{x}$ No. Values ${ }^{\mathrm{b}}$ & & & $\begin{array}{l}-0.00781^{*} \\
(0.00302)\end{array}$ & $\begin{array}{c}-0.000963 * * \\
(0.000166)\end{array}$ \\
\hline Specialization & $\begin{array}{c}1.072 \\
(1.619)\end{array}$ & $\begin{array}{c}1.029 \\
(1.594)\end{array}$ & $\begin{array}{l}1.293 \\
(1.622)\end{array}$ & $\begin{array}{r}-0.0664 \\
(0.158)\end{array}$ \\
\hline US News Rankings & $\begin{array}{l}-0.227 \\
(0.304)\end{array}$ & $\begin{array}{l}-0.242 \\
(0.305)\end{array}$ & $\begin{array}{l}-0.237 \\
(0.306)\end{array}$ & $\begin{array}{c}0.0235 \\
(0.0164)\end{array}$ \\
\hline Magnet Status & $\begin{array}{c}0.569 \\
(0.668)\end{array}$ & $\begin{array}{c}0.654 \\
(0.691)\end{array}$ & $\begin{array}{c}0.715 \\
(0.670)\end{array}$ & $\begin{array}{c}0.0152 \\
(0.0275)\end{array}$ \\
\hline HA Readmissions Prevention (2009) & $\begin{array}{c}0.731 * * \\
(0.132)\end{array}$ & $\begin{array}{c}0.733 * * \\
(0.136)\end{array}$ & $\begin{array}{c}0.689 * * \\
(0.135)\end{array}$ & \\
\hline Return on Assets (2009) & & & & $\begin{array}{c}0.659 * * \\
(0.174)\end{array}$ \\
\hline CEO Tenure & $\begin{array}{c}0.0240 \\
(0.0391)\end{array}$ & $\begin{array}{c}0.0266 \\
(0.0396)\end{array}$ & $\begin{array}{c}0.0218 \\
(0.0398)\end{array}$ & $\begin{array}{c}-0.000584 \\
(0.00297)\end{array}$ \\
\hline Hospital Size $^{c}$ & $\begin{array}{c}0.0000 \\
(0.0000)\end{array}$ & $\begin{array}{c}0.0000 \\
(0.0000)\end{array}$ & $\begin{array}{c}0.0000 \\
(0.0000)\end{array}$ & $\begin{array}{c}0.0000 \\
(0.0000)\end{array}$ \\
\hline Market Concentration & $\begin{array}{l}1.980^{\mathrm{t}} \\
(1.026)\end{array}$ & $\begin{array}{l}1.900^{\mathrm{t}} \\
(1.047)\end{array}$ & $\begin{array}{l}2.339^{*} \\
(1.095)\end{array}$ & $\begin{array}{c}0.122^{\mathrm{t}} \\
(0.0720)\end{array}$ \\
\hline System Membership & $\begin{array}{l}-0.135 \\
(0.266)\end{array}$ & $\begin{array}{l}-0.103 \\
(0.280)\end{array}$ & $\begin{array}{l}-0.131 \\
(0.281)\end{array}$ & $\begin{array}{l}-0.0251 \\
(0.0237)\end{array}$ \\
\hline Private Ownership & $\begin{array}{r}-0.0319 \\
(0.290)\end{array}$ & $\begin{array}{c}-0.0502 \\
(0.281)\end{array}$ & $\begin{array}{r}-0.0477 \\
(0.277)\end{array}$ & $\begin{array}{l}0.0415^{t} \\
(0.0235)\end{array}$ \\
\hline Medicaid Share & $\begin{array}{c}0.604 \\
(1.434)\end{array}$ & $\begin{array}{c}0.964 \\
(1.427)\end{array}$ & $\begin{array}{c}0.475 \\
(1.502)\end{array}$ & $\begin{array}{c}-0.0480 \\
(0.119)\end{array}$ \\
\hline Teaching Status & $\begin{array}{c}0.925 \\
(0.727)\end{array}$ & $\begin{array}{c}0.941 \\
(0.728)\end{array}$ & $\begin{array}{c}1.202 \\
(0.751)\end{array}$ & $\begin{array}{c}0.0262 \\
(0.0499)\end{array}$ \\
\hline Technology Index & $\begin{array}{l}0.230 * \\
(0.111)\end{array}$ & $\begin{array}{l}0.231 * \\
(0.114)\end{array}$ & $\begin{array}{l}0.225^{\mathrm{t}} \\
(0.114)\end{array}$ & $\begin{array}{l}-0.00393 \\
(0.00966)\end{array}$ \\
\hline Difficulty of Vision & $\begin{array}{l}-0.0519^{*} \\
(0.0232)\end{array}$ & $\begin{array}{l}-0.0520^{*} \\
(0.0235)\end{array}$ & $\begin{array}{l}-0.0556^{*} \\
(0.0233)\end{array}$ & $\begin{array}{l}-0.000978 \\
(0.00276)\end{array}$ \\
\hline Importance of Vision & $\begin{array}{l}0.0598 * \\
(0.0296)\end{array}$ & $\begin{array}{l}0.0565^{t} \\
(0.0304)\end{array}$ & $\begin{array}{l}0.0578^{t} \\
(0.0297)\end{array}$ & $\begin{array}{l}-0.00165 \\
(0.00224)\end{array}$ \\
\hline Categorical Specificity of Vision & $\begin{array}{c}-0.0124 \\
(0.00923)\end{array}$ & $\begin{array}{l}-0.0169 \\
(0.0113)\end{array}$ & $\begin{array}{l}-0.0135 \\
(0.0112)\end{array}$ & $\begin{array}{c}0.000687 \\
(0.000930)\end{array}$ \\
\hline Prosocial Value of Vision & $\begin{array}{c}-0.0659 \\
(0.0520)\end{array}$ & $\begin{array}{l}-0.0658 \\
(0.0542)\end{array}$ & $\begin{array}{l}-0.0542 \\
(0.0507)\end{array}$ & $\begin{array}{c}0.00154 \\
(0.00379)\end{array}$ \\
\hline Gunning Fog Index & $\begin{array}{c}-0.0309 * \\
(0.0148)\end{array}$ & $\begin{array}{l}-0.0274^{\mathrm{t}} \\
(0.0162)\end{array}$ & $\begin{array}{l}-0.0309^{t} \\
(0.0161)\end{array}$ & $\begin{array}{l}-0.00350 * \\
(0.00174)\end{array}$ \\
\hline Constant & $\begin{array}{l}20.50^{\mathrm{t}} \\
(10.69)\end{array}$ & $\begin{array}{l}20.54^{\mathrm{t}} \\
(11.00)\end{array}$ & $\begin{array}{l}24.17^{*} \\
(10.92)\end{array}$ & $\begin{array}{c}0.197 \\
(0.153) \\
\end{array}$ \\
\hline Observations & 92 & 92 & 92 & 143 \\
\hline R-squared & 0.594 & 0.605 & 0.619 & 0.528 \\
\hline
\end{tabular}

a. Heart attack readmission prevention represents core dependent variable. ROA is a robustness check.

b. Variables are demeaned.

c. For this variable, all coefficients and standard errors are 0 when rounded to four decimal places.

d. Robust standard errors in parentheses.

${ }^{\mathrm{e}}$. $* * p<0.01, * p<0.05,{ }^{\mathrm{t}} p<0.1$ 
Andrew M. Carton (carton@wharton.upenn.edu) is an assistant professor of management in the Wharton School at the University of Pennsylvania. He obtained his Ph.D. from Duke University's Fuqua School of Business. His research focuses on the linkages between intergroup relations, leadership, and goal systems in organizations.

Chad Murphy (chad.murphy@oregonstate.edu) is an assistant professor of management in the College of Business at Oregon State University. He received his Ph.D. in business administration from the Pennsylvania State University. His research focuses on identity, image, and leadership.

Jonathan R. Clark (jonrclark@psu.edu) is an assistant professor in the Department of Health Policy and Administration at Pennsylvania State University. He received his Ph.D. in Health Policy/Management from Harvard University. His research focuses on organization design and leadership in the health care industry. 